\title{
High capacity hydrogen storage materials: attributes for automotive applications and techniques for materials discovery
}

\author{
Jun Yang, ${ }^{* a}$ Andrea Sudik, ${ }^{a}$ Christopher Wolverton ${ }^{b}$ and Donald J. Siegel $\dagger^{a}$ \\ Received 23rd December 2008 \\ First published as an Advance Article on the web 14th September 2009 \\ DOI: $10.1039 / \mathbf{b 8 0 2 8 8 2 f}$
}

Widespread adoption of hydrogen as a vehicular fuel depends critically upon the ability to store hydrogen on-board at high volumetric and gravimetric densities, as well as on the ability to extract/insert it at sufficiently rapid rates. As current storage methods based on physical means - high-pressure gas or (cryogenic) liquefaction - are unlikely to satisfy targets for performance and cost, a global research effort focusing on the development of chemical means for storing hydrogen in condensed phases has recently emerged. At present, no known material exhibits a combination of properties that would enable high-volume automotive applications. Thus new materials with improved performance, or new approaches to the synthesis and/or processing of existing materials, are highly desirable. In this critical review we provide a practical introduction to the field of hydrogen storage materials research, with an emphasis on (i) the properties necessary for a viable storage material, (ii) the computational and experimental techniques commonly employed in determining these attributes, and (iii) the classes of materials being pursued as candidate storage compounds. Starting from the general requirements of a fuel cell vehicle, we summarize how these requirements translate into desired characteristics for the hydrogen storage material. Key amongst these are: (a) high gravimetric and volumetric hydrogen density, (b) thermodynamics that allow for reversible hydrogen uptake/release under near-ambient conditions, and (c) fast reaction kinetics. To further illustrate these attributes, the four major classes of candidate storage materials - conventional metal hydrides, chemical hydrides, complex hydrides, and sorbent systems - are introduced and their respective performance and prospects for improvement in each of these areas is discussed. Finally, we review the most valuable experimental and computational techniques for determining these attributes, highlighting how an approach that couples computational modeling with experiments can significantly accelerate the discovery of novel storage materials (155 references).

${ }^{a}$ Ford Motor Company Research and Advanced Engineering, 2101 Village Rd, RIC/MD1170, Dearborn, MI 48121, USA. E-mail: jyang27@ford.com,asudik@ford.com

${ }^{b}$ Department of Materials Science and Engineering, Northwestern University, 2220 Campus Dr., Evanston, IL 60208, USA.

E-mail: c-wolverton@northwestern.edu

$\dagger$ Present address: Mechanical Engineering Department, University of Michigan, 2250 G. G. Brown Laboratory, 2350 Hayward St., Ann Arbor, MI 48109-2125, USA. E-mail: djsiege@umich.edu

\section{Introduction and motivation}

Continuing growth in global population coupled with the rapid pace of industrialization in Asia suggests that the number of light duty vehicles in use worldwide will approximately triple during the 2000-2050 timeframe. ${ }^{1}$ As today's vehicle fleet is based almost entirely upon the internal combustion engine (ICE), the transportation sector is highly

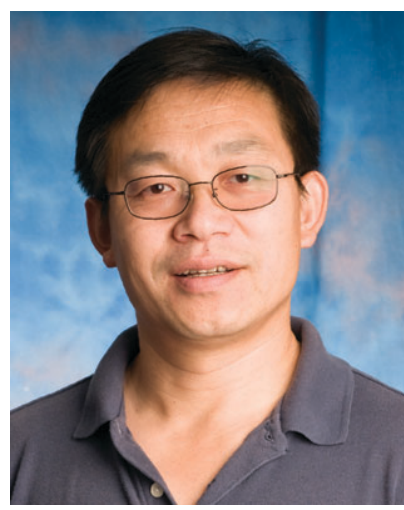

Jun Yang
Jun Yang is a Technical Expert of materials for energy conversion and storage at Ford Motor Company. He received his BE (1987) and PhD (1992) in materials science and engineering from the University of Science \& Technology Beijing, and $M B A$ from the Ross School of Business at University of Michigan (2005). He did post-doctoral work on materials physics at Peking University and McGill University.

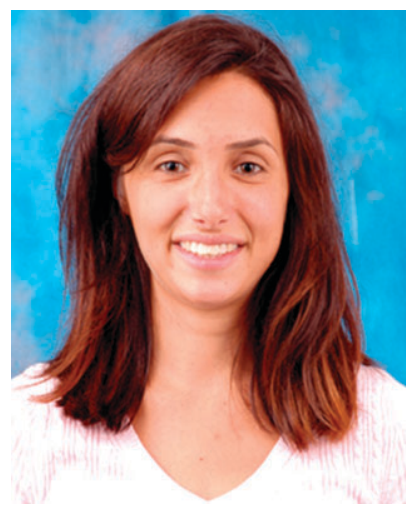

Andrea Sudik received her BA in chemistry from Kalamazoo College in 2000 and obtained her PhD from the University of Michigan in 2005. She joined the Ford Motor Company in 2005 where she is a Research Scientist currently working within the Fuel Cell and Hybrid Electric Vehicle Research Department. 
dependant on petroleum-derived fuels: in the U.S. approximately $2 / 3$ of petroleum consumption can be attributed to use in transportation. ${ }^{2}$ Consequently, transportation is a significant source of carbon dioxide emissions. In 2004, light-duty passenger vehicles were responsible for approximately $20 \%$, $17 \%$ and $11 \%$ of US, EU-15 and global fossil fuel emissions, respectively. ${ }^{3}$ In order to stabilize global $\mathrm{CO}_{2}$ levels while simultaneously meeting the mobility needs of a growing population, the development of new, environmentallysustainable technologies for personal mobility is essential. ${ }^{4}$

Hydrogen-powered fuel cell vehicles (FCVs) are one of a small number of technologies being pursued as an alternative to the gasoline ICE. [Other technologies include battery electric vehicles, (plug-in) hybrid electric vehicles, biofueled vehicles, and hydrogen-fueled internal combustion engine vehicles.] As an energy carrier for use in vehicle applications, hydrogen has several advantages: it has the highest energy density by weight of any common fuel; it can be produced renewably from a variety of (non-fossil) feed-stocks; ${ }^{5}$ and when combined with oxygen in a proton exchange membrane (PEM) fuel cell, ${ }^{6}$ it can be used to generate power with only water as a by-product. This latter attribute positions FCVs as one of only two options (the other being battery electric vehicles) for achieving a vehicle that has zero emissions. Demonstration fleets of FCVs have been produced by nearly all major automobile manufacturers: a fleet of approximately 30 FCVs based on the 2005 U.S. Focus developed by the Ford Motor Company has amassed more than one million miles in real-world use. These vehicles achieve fuel economies of $80.5 \mathrm{~km} / \mathrm{kg} \mathrm{H}$, (equal to $21.2 \mathrm{~km} / \mathrm{L}$ gasoline on an energyequivalence basis), ${ }^{7}$ which is $83 \%$ higher than the fuel economy of the gasoline ICE Focus. ${ }^{8}$

Despite these benefits, several technological hurdles must be overcome before FCVs can achieve widespread commercialization. $^{5}$ These include: the efficient production and distribution of hydrogen, fuel cells of sufficient durability to allow for long-term use, fuel cell catalysts that minimize precious-metal content, high-temperature/low-humidity proton exchange membranes, and efficient means for on board storage of hydrogen. The latter topic - the so-called "hydrogen storage problem"- which is the subject of the present Review, has sparked intense scientific interest in the chemistry and materials science communities during the past decade, ${ }^{9}$ largely reflecting the wide range of techniques being pursued as possible solutions. As we describe below, a solution to this problem will likely require the development of an as-ofyet unknown material capable of storing hydrogen at near ambient conditions, while exhibiting high $\mathrm{H}_{2}$ density and fast reaction kinetics.

\section{Automotive constraints}

Ideally, the capabilities of a FCV should closely resemble those of today's vehicles: it should be safe, able to transport a small family and their cargo, affordable (to manufacture, purchase, and operate), durable, and able to travel distances on the order of $500 \mathrm{~km}$ (300 mi) or more before refueling. Assuming an average fuel economy of $10.6 \mathrm{~km} / \mathrm{L}$ (25 mi/gallon), ${ }^{10}$ a conventional ICE vehicle of today would require $\sim 46 \mathrm{~L}$ (12 gallons) of gasoline (equivalent to $1450 \mathrm{MJ}^{7}$ ) for a $483 \mathrm{~km}$ range. In comparison, a FCV with an efficiency of twice $^{11}$ that of an ICE vehicle would only require $725 \mathrm{MJ}$ to travel the same distance. As the energy content of one kilogram of hydrogen is approximately equal to one gallon of gasoline [based on their respective lower heating values (LHV)], roughly $6 \mathrm{~kg}$ of hydrogen would need to be stored on board the vehicle.

At STP, hydrogen is a gas with density of $0.089 \mathrm{~g} / \mathrm{L}$. Therefore $6 \mathrm{~kg}$ of hydrogen at STP will occupy a spherical volume with a $5 \mathrm{~m}$ diameter, which is large enough to completely enclose a moderately-sized sedan. Due to its low density, most current FCVs store hydrogen under high

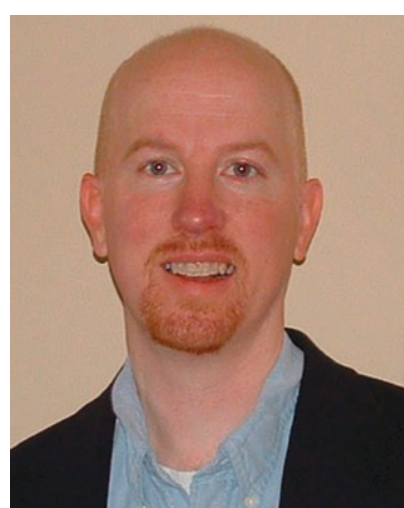

Christopher Wolverton
Christopher Wolverton is a Professor in the Materials Science Department at Northwestern University. Before joining the faculty, he worked at the Research and Innovation Center at Ford Motor Company, as group leader for the Hydrogen Storage and Nanoscale Modeling Group. He received his BS degree in Physics from the University of Texas at Austin and his PhD degree in Physics from the University of California at Berkeley. He then performed postdoctoral work and was later a staff member at the National Renewable Energy Laboratory (NREL). His research interests include computational studies of a variety of energy-efficient and environmentally friendly materials via first-principles atomistic calculations and "multiscale" methodologies for linking atomistic and microstructural scales.

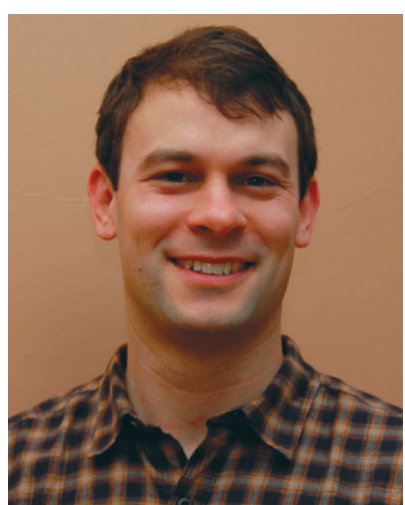

Donald J. Siegel
Don Siegel received his doctorate degree in physics from the University of Illinois at Urbana-Champaign. He then performed postdoctoral research in the Materials Physics Department at Sandia National Laboratories (Livermore, CA), and was subsequently a National Research Council Fellow at the Center for Computational Materials Science at the U.S Naval Research Laboratory. From 2005-2009 he was a Technical Expert at Ford Motor Company, where he led the Fuel Cell and Hydrogen Storage Materials group. He is currently an Assistant Professor in the Mechanical Engineering Department at the University of Michigan. His research interests lie in the fields of energy storage and computational materials science. 
pressure, typically at 35 or $70 \mathrm{MPa}$. However, even at these high pressures the energy density of hydrogen is still far below that of gasoline: one liter of gasoline $(31.7 \mathrm{MJ} / \mathrm{L}, 8.8 \mathrm{kWh} / \mathrm{L})$ contains approximately six times as much energy as a liter of hydrogen compressed to $70 \mathrm{MPa}(4.7 \mathrm{MJ} / \mathrm{L}, 1.3 \mathrm{kWh} / \mathrm{L})$. Moreover, to achieve weights consistent with vehicular use, the vessels used to contain hydrogen at these pressures are constructed of costly, lightweight carbon fiber. As a result, they are roughly an order of magnitude more expensive than an equivalent (plastic) gasoline tank. ${ }^{12}$ In our experience, today's 35-70 MPa composite pressure vessel systems achieve energy densities of $1.2-1.5 \mathrm{kWh} / \mathrm{kg}$ and $0.6-0.8 \mathrm{kWh} / \mathrm{L}$, which fall far short of the DOE 2015 targets (see below and Table 1). At present no clear pathway exists for compressed hydrogen to overcome these deficiencies in performance ${ }^{13}$ and cost. As an alternative to compression, the density of hydrogen can also be increased by liquefaction at $20 \mathrm{~K}$. However, the low efficiency of the liquefaction process, which currently requires about a third (or more) of the hydrogen's energy content, ${ }^{14}$ makes this approach unattractive from an energy efficiency standpoint.

\section{Performance targets}

In light of the performance and cost challenges associated with physical storage, research exploring chemical means for storing hydrogen has grown significantly. ${ }^{15}$ To guide efforts in this emerging field towards technologies relevant for vehicle applications, the U.S. Department of Energy (DOE), in consultation with the U.S. Council for Automotive Research (USCAR), has established an evolving set of technical targets for on-board hydrogen storage systems. ${ }^{16,17}$ The previous set ${ }^{17}$ of these targets was established in 2003, coinciding with the announcement of the DOE Grand Challenge in hydrogen storage $R \& D$. A revised set ${ }^{16}$ of targets was introduced in early 2009. A subset of both the "old" 2003 and "new" 2009 targets is summarized in Table 1. While in some cases the new targets are identical to the previous values (delivery temperature and kinetics), the gravimetric and volumetric capacity targets have been reduced. In addition, a new "Ultimate" target category was added to represent the desired end state of technology development.

A key difference between the 2003 and 2009 targets is the methodology used in their derivation. The old targets were developed at a time when little FCV data was available, and it was therefore necessary to make assumptions regarding the efficiency, packaging, and power \& energy densities of the FC and hydrogen storage systems. Perhaps the most significant of these assumptions pertains to packaging: it was assumed that the gross architecture of a FCV would not differ significantly from that of an ICE vehicle. Hence the mass and volume of the hydrogen storage system should be roughly equivalent to that of a gasoline fuel system on a conventional vehicle. This requirement for similarity between the hydrogen and gasoline fuel systems resulted in high gravimetric and volumetric hydrogen storage targets $\left(9 \mathrm{wt}^{\%} \mathrm{H}_{2}\right.$ and $\left.81 \mathrm{~g} \mathrm{H}_{2} / \mathrm{L}\right)$.

Much experience has been gained in the development of FCV in the years following the creation of the original targets. For example, several automobile manufacturers have introduced demonstration vehicles or entire fleets. ${ }^{18}$ As a consequence, understanding of FCV design, performance, and customer expectations has grown substantially. This knowledge served as the basis for the revised targets, and allows for fewer assumptions to be made in the target setting analysis. For example, rather than guessing at the fuel economy of a future FCV, the revised targets adopt the fuel economy of the existing DOE vehicle fleet. ${ }^{18}$ Similarly, the measured masses and volumes of the hydrogen storage systems were taken as representative of realistic packaging constraints. In total, the availability of real FCV data has led to a more accurate set of targets. Further information regarding the targets and their derivation can be found in ref. 16. One important aspect of the targets which is commonly overlooked is the fact that they refer to the properties of the entire storage system, and therefore take into account the mass, volume, cost (etc.) of any auxiliary components associated with the system. As a consequence, a viable storage material must possess properties exceeding the system requirements. Furthermore, the targets must be met simultaneously. In other words, a material that satisfies but one or two of the targets, while possibly representing an important breakthrough, does not present a solution to the hydrogen storage problem. Below we provide a brief overview of the targets listed in Table 1.

\section{Gravimetric \& volumetric density}

A means for storing hydrogen on-board a vehicle should be relatively compact and light weight. To derive the Ultimate targets for volumetric and gravimetric hydrogen density, data for the storage systems present on the DOE Technology Validation Fleet were used. ${ }^{18}$ The masses and volumes of

Table 1 Summary of "old" (2003) and "new" (2009) $)^{b}$ DOE hydrogen storage targets

\begin{tabular}{|c|c|c|c|c|c|c|}
\hline \multirow[b]{2}{*}{ Storage parameter } & \multirow[b]{2}{*}{ Units } & \multicolumn{2}{|c|}{ Old targets (2003) } & \multicolumn{3}{|c|}{ New targets (2009) } \\
\hline & & 2010 & 2015 & 2010 & 2015 & Ultimate \\
\hline \multirow[t]{2}{*}{ System gravimetric capacity } & $\mathrm{kWh} / \mathrm{kg}$ & 2 & 3 & 1.5 & 1.8 & 2.5 \\
\hline & $\mathrm{wt} \% \mathrm{H}_{2}$ & 6 & 9 & 4.5 & 5.5 & 7.5 \\
\hline \multirow[t]{2}{*}{ System volumetric capacity } & $\mathrm{kWh} / \mathrm{L}$ & 1.5 & 2.7 & 0.9 & 1.3 & 2.3 \\
\hline & $\mathrm{g} \mathrm{H}_{2} / \mathrm{L}$ & 45 & 81 & 28 & 40 & 70 \\
\hline $\mathrm{H}_{2}$ delivery temp. (to $\mathrm{FC}$ ) & ${ }^{\circ} \mathrm{C}$ & $-40 / 85$ & $-40 / 85$ & $-40 / 85$ & $-40 / 85$ & $-40 / 95-105$ \\
\hline Operating pressure (min./max.) & $\mathrm{MPa}$ & $0.4 / 10$ & $0.3 / 10$ & $0.5 / 1.2$ & $0.5 / 1.2$ & $0.3 / 1.2$ \\
\hline Kinetics & $\left(\mathrm{g} \mathrm{H}_{2} / \mathrm{s}\right) / \mathrm{kW}$ & 0.02 & 0.02 & 0.02 & 0.02 & 0.02 \\
\hline Cost & \$/kWh net & 4 & 2 & & To be determined & \\
\hline${ }^{a}$ Ref. $17 .{ }^{b}$ Ref. 16. & & & & & & \\
\hline
\end{tabular}


these systems were taken as representative of the space and weight increments that could be realistically allocated to hydrogen storage in a future FCV. Measured fuel economies and driving ranges were then used to determine the quantity of stored hydrogen needed to achieve a $805 \mathrm{~km}(500 \mathrm{mi})^{19}$ driving range. Dividing the quantity of stored hydrogen by the average fleet storage system mass and volume yields the new target values of $7.5 \mathrm{wt} \% \mathrm{H}_{2}$ and $70 \mathrm{~g} \mathrm{H}_{2} / \mathrm{L} .{ }^{20}$ Compared to the old 2015 targets $\left(9 \mathrm{wt} \%\right.$ and $\left.81 \mathrm{~g} \mathrm{H}_{2} / \mathrm{L}\right)$, the Ultimate targets represent a $17 \%$ and $14 \%$ decline in gravimetric and volumetric hydrogen density, respectively.

The new $2010\left(4.5 \mathrm{wt} \% \mathrm{H}_{2}, 28 \mathrm{~g} \quad \mathrm{H}_{2} / \mathrm{L}\right)$ and 2015 ( $5.5 \mathrm{wt} \% \mathrm{H}_{2}, 40 \mathrm{~g} \mathrm{H}_{2} / \mathrm{L}$ ) targets were derived by interpolating between the Ultimate targets and current state-of-the-art compressed hydrogen storage systems. The 2010 milestone captures performance that is consistent with early market penetration of FCV into low volume vehicles and fleets. The 2015 targets would allow for significant market penetration of FCV across mid-sized vehicles, and represent a key (go/no-go) decision point for widespread commercialization.

\section{Temperature and pressure}

The temperature range over which a hydrogen storage system should operate is dictated both by the environment and the requirements of the fuel cell. The lower temperature limit in Table $1\left(-40^{\circ} \mathrm{C}\right)$ largely reflects requirements for cold weather operation. On the other hand, the high temperature target (85 ${ }^{\circ} \mathrm{C}$ in $2010-2015$, increasing to $95-105{ }^{\circ} \mathrm{C}$ Ultimate) is based on the operating temperature limit of the fuel cell. For storage systems where hydrogen release is an endothermic process, it may also be possible to use the fuel cell's coolant heat to trigger desorption if the enthalpy of the desorption reaction falls within a suitable window (see below).

The minimum acceptable $\mathrm{H}_{2}$ pressure supplied by the storage system, targeted at $0.5-0.3 \mathrm{MPa}$ (5-3 bar), is dictated by the requirements of the fuel cell. The maximum pressure target, 1.2 $\mathrm{MPa}$, is chosen so as to not require extraordinary down-regulation of hydrogen pressure from the storage system. Nevertheless, since current FCVs routinely use highly pressurized 35-70 MPa systems, it may be reasonable to relax this target in favor of allowing higher pressures.

\section{Kinetics}

The hydrogen fuel system should be able to provide fuel at a rate suitable to power a fuel cell over a range of driving conditions. For an $80 \mathrm{~kW}$ fuel cell, the targeted value of 0.02 $\left(\mathrm{g} \mathrm{H}_{2} / \mathrm{s}\right) / \mathrm{kW}$ amounts to a requirement of $1.6 \mathrm{~g} \mathrm{H}_{2} / \mathrm{s}$ from the storage system. While not discussed in detail here, the kinetic properties of the system will also impact the rate of hydrogen uptake during refueling. Assuming a $5 \mathrm{~kg}$ fill of hydrogen, targeted refill times range from 4.2 (2010) to $2.5 \mathrm{~min}$ (Ultimate). ${ }^{16}$ These times are comparable to those needed to refill a gasoline vehicle.

\section{Cost}

While not a materials performance metric, cost is a crucial factor in determining the viability of any new technology, and therefore should play a role in limiting the range of candidate storage technologies. While essentially all of the other DOE storage targets have been revised, at the time of this writing no new cost targets have been proposed. This delay is due to the desire to coordinate the cost targets with changes to other vehicle cost targets, such as those involving the fuel cell. When available, updated cost information can be found in ref. 16 .

For reference, the old cost targets are summarized in Table 1. It is probable that these values will be revised upwards in recognition of the fact that hydrogen storage systems will likely require more complex, and thus more costly, designs and materials compared to current gasoline fuel systems.

Note that it is possible to estimate an upper limit for the cost of the storage material itself by combining the cost target (when it becomes available) with the target for gravimetric density. For example, assuming a $6 \mathrm{~kg} \mathrm{H}_{2}$ capacity and neglecting all costs other than the storage material, a $10 \mathrm{wt} \%$ material that achieves a hypothetical system cost target of $\$ 10 / \mathrm{kWh}$ should cost less than $\$ 33.33 / \mathrm{kg}$.

\section{Candidate hydrogen storage materials}

It is possible to increase the density of hydrogen beyond what can be achieved via compression or liquefaction through materials-based hydrogen storage. This is possible because in many hydride-type materials, hydrogen is packed with $\mathrm{H}-\mathrm{H}$ distances as small as 2.1 Angstroms, ${ }^{21}$ resulting in hydrogen densities up to $170 \mathrm{~g} \mathrm{H}_{2} / \mathrm{L}^{22}$ - a factor of more than 2 greater than the density of liquid hydrogen. The high hydrogen densities achievable using materials-based storage makes this approach an attractive (and perhaps the only) means for achieving the Ultimate DOE storage targets.

The strength of interaction between hydrogen and a host material ranges from weak van der Waals interactions typical of the physisorptive binding of molecular $\mathrm{H}_{2}$, to the strong chemisorptive binding of atomic hydrogen. ${ }^{23}$ In general, hydrogen storage materials can be categorized using a combination of two criteria: (i) the nature of their sorption mechanism (e.g. physisorption or chemisorption), and (ii) by the identity of the material itself. (Note that this grouping, although now based on convention, is not unique: it is possible to identify materials which fit equally well within more than one class.) In the present Review, we limit the scope of our discussion to those categories of storage materials which in our assessment are the most relevant and which have received the most attention from the research community: (1) conventional metal hydrides, (2) complex hydrides, (3) sorbents, and (4) chemical hydrides. In the following sections we review the relevant features of these four materials classes.

\section{Conventional metal hydrides}

Perhaps conceptually the simplest and most thoroughly studied method of storing hydrogen in a solid involves the reaction of $\mathrm{H}_{2}$ with a metal or metal alloy (M) to form a metal hydride $\left(\mathrm{MH}_{x}\right)$ :

$$
\mathrm{M}+(x / 2) \mathrm{H}_{2} \rightleftharpoons \mathrm{MH}_{x}
$$

Many metal hydrides are stable at ambient conditions, and the exothermic formation enthalpy for these compounds reflects the favorable bonding between metal and $\mathrm{H}$ atoms 


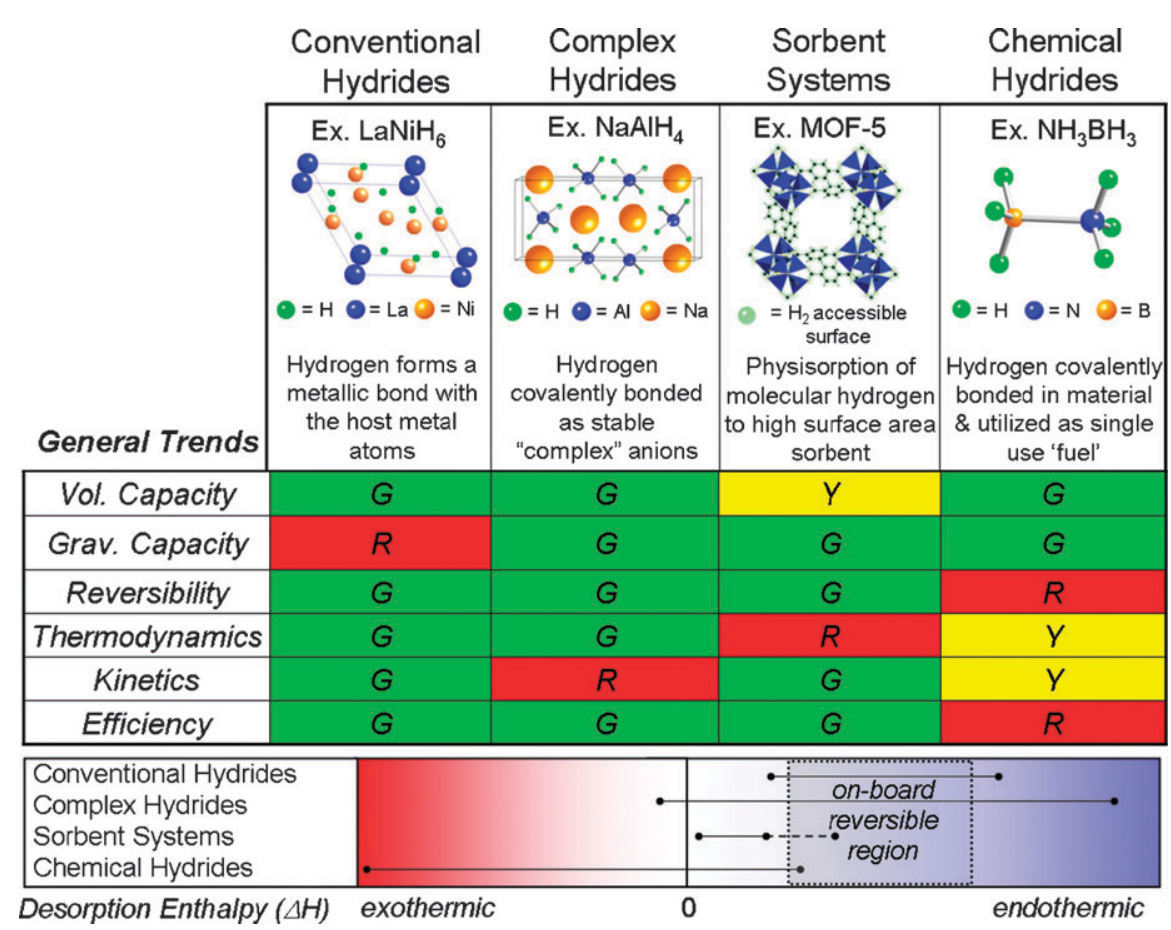

Fig. 1 Overview of the properties of the major hydrogen storage materials classes. Trends for technical challenges for each class are delineated by color code: Red indicates significant challenges remain towards achieving DOE targets; Green signifies satisfactory performance; Yellow indicates some improvement is required. Trends and reaction enthalpies are meant to be generally descriptive for the entire class; exceptions are possible for individual materials. Reversibility and thermodynamic attributes are differentiated according to a practical on-board perspective: reversibility is taken as the potential for each class of materials to be capable of being reversed on-board, whereas thermodynamics dictates the reasonableness of the theoretical operating temperature and pressure conditions for hydrogen charge and discharge. The 'spillover' concept (see section IV) applies for sorbent systems and extends the desorption enthalpy for these compounds into the on-board reversible region (dashed line in bottom panel).

(see Fig. 1, column 1 for an overview of the properties of conventional metal hydrides). In some cases, the crystal structure of the metal does not topologically change upon insertion of $\mathrm{H}$ atoms into interstitial sites, and thus these hydrides are referred to as interstitial hydrides. Examples of interstitial hydrides include $\mathrm{PdH},(\mathrm{Vi}-\mathrm{Ti}-\mathrm{Fe}) \mathrm{H}_{2}$ and $\mathrm{LaNi}_{5} \mathrm{H}_{x}$ (see Table 2, reactions 1 and 2). In other cases, a new structural type is formed upon hydrogen incorporation. Examples of these so-called structural hydrides include $\mathrm{MgH}_{2}$ and $\mathrm{AlH}_{3}$ (Table 2, reactions 3 and 9).

Conventional metal hydrides have been studied for various hydrogen storage applications for more than a half century. For use in automotive applications, however, the gravimetric density of these materials is generally too low, or the thermodynamics of $\mathrm{H}$ bonding is either too strong or too weak for easy hydrogen insertion/removal (we discuss thermodynamics in more detail below). For example, alane $\left(\mathrm{AlH}_{3}\right)$ contains a large amount of hydrogen by weight $(\sim 10 \mathrm{wt} \%)$. However, due to a weak binding energy, reflected in the low $5-8 \mathrm{~kJ} / \mathrm{mol} \mathrm{H}_{2}$ enthalpy $(\Delta H)$ for $\mathrm{H}_{2}$ desorption (Table 2), it is impossible to directly recharge alane from $\mathrm{Al}$ and $\mathrm{H}_{2}$ using moderate pressures. Magnesium hydride $\left(\mathrm{MgH}_{2}\right)$ also possesses a reasonably high gravimetric capacity, but suffers from the opposite problem in that the binding energy of this compound is too strong $\left(\Delta H=66-75 \mathrm{~kJ} / \mathrm{mol} \mathrm{H}_{2}\right),{ }^{24}$ requiring $\sim 290{ }^{\circ} \mathrm{C}$ to desorb $\mathrm{H}_{2}$ at $0.1 \mathrm{MPa}$. On the other hand, metal hydrides with more moderate binding energies, such as $\mathrm{VH}_{2}$ and $\mathrm{LaNi}_{5} \mathrm{H}_{x}$, have good thermodynamics
( $\Delta H \sim 30-43 \mathrm{~J} / \mathrm{mol} \mathrm{H}_{2}$, Table 2), but are comprised of heavy transition and rare earth metals, and therefore have limited gravimetric densities.

Efforts at improving hydrogen capacity and reaction enthalpy of conventional metal hydrides have largely focused on alloying with other elements, and several categories of conventional metal hydrides have been developed: BCC-type alloys (e.g. $\mathrm{Fe}-\mathrm{Ti}, \mathrm{Ti}-\mathrm{Mo}$ and $\mathrm{V}$-based), $\mathrm{AB}_{5}$ alloys (e.g., $\mathrm{LaNi}_{5}$-type), $\mathrm{AB}_{2}$ alloys (e.g., $\mathrm{Ti}(\mathrm{Zr})-\mathrm{Mn}$-based), and Mg-based alloys (e.g., those based on $\mathrm{Mg}-\mathrm{Al}, \mathrm{Mg}_{2} \mathrm{Ni}, \mathrm{Mg}_{2} \mathrm{Cu}$, $\mathrm{Mg}_{2} \mathrm{FeH}_{6}, \mathrm{Mg}_{2} \mathrm{CoH}_{5}$ and $\left.\mathrm{Mg}_{7} \mathrm{Ti}(\mathrm{Pd}, \mathrm{Sc}) \mathrm{H}_{12.7}\right){ }^{25-27}$ Fig. 1 and reactions $1-3$ and 9 of Table 2 provide a summary of the conventional metal hydride category. A more detailed review of the properties of conventional metal hydrides can be found elsewhere. ${ }^{27,28}$

\section{Complex hydrides}

The term "complex hydrides" is used to describe a class of ionic hydrogen-containing compounds which are composed of metal cations (e.g. often lightweight alkali or alkaline earth $\mathrm{Li}$, $\mathrm{Na}, \mathrm{Mg}$, or Ca cations) and hydrogen-containing "complex" anions such as borohydrides $\left(\mathrm{BH}_{4}^{-}\right),{ }^{29-31}$ alanates $\left(\mathrm{AlH}_{4}{ }^{-}\right),{ }^{32}$ and amides $\left(\mathrm{NH}_{2}^{-}\right) \cdot{ }^{33}$ In this anionic complex, hydrogen atoms are covalently bonded to central atoms, for example boron, aluminium or nitrogen (see Fig. 1, column 2). As a consequence, complex hydrides are grouped under the chemisorptive hydrogen storage mechanism. Examples of 
Table 2 Summary of thermodynamic and theoretical capacity data for hydrogen storage reactions of recent interest. Data for $\Delta H_{\text {des }}$ [units $\left.\mathrm{kJ} /\left(\mathrm{mol} \mathrm{H}_{2}\right)\right]$ and $\Delta S_{\text {des }}\left[\right.$ units of $\mathrm{J} /\left(\mathrm{K} \mathrm{mol} \mathrm{H}_{2}\right)$ ] are taken from experiments unless otherwise noted

\begin{tabular}{|c|c|c|c|c|c|c|c|}
\hline $\begin{array}{l}\text { Rxn } \\
\text { no. }\end{array}$ & Reaction & $\mathrm{Wt} \% \mathrm{H}_{2}$ (ideal) & $\begin{array}{l}\mathrm{g} \mathrm{H}_{2} / \mathrm{L} \\
\text { (ideal) }\end{array}$ & Reversible $^{d}$ & $\Delta H_{\mathrm{des}}$ & $\Delta S_{\mathrm{des}}$ & Ref. \\
\hline 1 & $\mathrm{LaNi}_{5} \mathrm{H}_{6.5} \rightleftharpoons \mathrm{LaNi}_{5}+3.25 \mathrm{H}_{2}$ & 1.5 & 100 & Y & 30.8 & 108 & 27 \\
\hline 2 & $\mathrm{~V}_{0.85} \mathrm{Ti}_{0.1} \mathrm{Fe}_{0.05} \mathrm{H}_{2} \rightleftharpoons \mathrm{V}_{0.85} \mathrm{Ti}_{0.1} \mathrm{Fe}_{0.05}+\mathrm{H}_{2}$ & 3.7 & $\sim 170^{e}$ & $\mathrm{Y}$ & 43.2 & 140 & 88 \\
\hline 3 & $\mathrm{MgH}_{2} \rightleftharpoons \mathrm{Mg}+\mathrm{H}_{2}$ & 7.7 & 109 & $\mathrm{Y}$ & $62.3,^{b} 65.8-75.2$ & $131^{b}$ & 37 \\
\hline $4 \mathrm{a}$ & $\mathrm{NaAlH}_{4} \rightleftharpoons 1 / 3 \mathrm{Na}_{3} \mathrm{AlH}_{6}+2 / 3 \mathrm{Al}+\mathrm{H}_{2}{ }^{a}$ & 3.7 & 52 & Y & $37-2$ & & 95 \\
\hline $4 b$ & $\mathrm{Na}_{3} \mathrm{AlH}_{6} \rightleftharpoons 3 \mathrm{NaH}+\mathrm{Al}+1.5 \mathrm{H}_{2}^{a}$ & 1.9 & 43 & $\mathrm{Y}$ & 47 & & \\
\hline 5 & $\mathrm{Mg}\left(\mathrm{NH}_{2}\right)_{2}+2 \mathrm{LiH} \rightleftharpoons \mathrm{Li}_{2} \mathrm{Mg}(\mathrm{NH})_{2}+2 \mathrm{H}_{2}$ & 5.6 & 66 & $\mathrm{Y}$ & $38.9-44.1,48^{b}$ & & 96,97 \\
\hline 6 & $\mathrm{LiBH}_{4} \rightleftharpoons \mathrm{LiH}+\mathrm{B}+3 / 2 \mathrm{H}_{2}$ & 13.9 & 93 & $\mathrm{Y}^{f}$ & $62.8^{b} 67,74$ & $115,103^{b}$ & $35,37,98$ \\
\hline $6 \mathrm{a}$ & $12 \mathrm{LiBH}_{4} \rightleftharpoons \mathrm{Li}_{2} \mathrm{~B}_{12} \mathrm{H}_{12}+10 \mathrm{LiH}+13 \mathrm{H}_{2}$ & 10.0 & 35 & & $44.4^{b}$ & $97^{b}$ & $99-102$ \\
\hline $6 b$ & $\mathrm{Li}_{2} \mathrm{~B}_{12} \mathrm{H}_{12} \rightleftharpoons 2 \mathrm{LiH}+12 \mathrm{~B}+5 \mathrm{H}_{2}$ & 6.5 & 60 & & $117^{b}$ & $120^{b}$ & $99-102$ \\
\hline 7 & $2 \mathrm{LiBH}_{4}+\mathrm{MgH}_{2} \rightleftharpoons \mathrm{MgB}_{2}+2 \mathrm{LiH}+4 \mathrm{H}_{2}$ & 11.6 & 96 & $\mathrm{Y}$ & $50.4,^{b} 41$ & $108^{b}$ & 35,37 \\
\hline 8 & $\mathrm{Li}_{4} \mathrm{BN}_{3} \mathrm{H}_{10} \rightleftharpoons \mathrm{Li}_{3} \mathrm{BN}_{2}+\mathrm{LiNH}_{2}+4 \mathrm{H}_{2}$ & $8.9(>10)^{103}$ & 88 & $\mathrm{~N}$ & $12.8^{b}$ & $111^{b}$ & 41,104 \\
\hline 9 & $\mathrm{AlH}_{3} \rightleftharpoons \mathrm{Al}+3 / 2 \mathrm{H}_{2}$ & 10 & 148 & $\mathrm{~N}$ & $4.6^{b} 7.8$ & & 105 \\
\hline $10 \mathrm{a}$ & $\mathrm{NH}_{3} \mathrm{BH}_{3} \rightleftharpoons\left[\mathrm{NH}_{2} \mathrm{BH}_{2}\right]_{x}+\mathrm{H}_{2}$ & 6.5 & 96 & $\mathrm{~N}$ & $-6,^{b}-21.7$ & & 106,107 \\
\hline $10 \mathrm{~b}$ & {$\left[\mathrm{NH}_{2} \mathrm{BH}_{2}\right]_{x} \rightleftharpoons[\mathrm{NHBH}]_{x}+\mathrm{H}_{2}$} & 7.0 & $(10 a+10 b)$ & $\mathrm{N}$ & $-40,{ }^{b}-(23.9-15.4)$ & & 106,108 \\
\hline 11 & MOF-177: $\mathrm{H}_{2} \rightleftharpoons \mathrm{MOF}-177+\mathrm{H}_{2}^{c}$ & $\begin{array}{l}7.5 \text { (surface excess) } \\
11 \text { (absolute, } \\
\text { incl. } \mathrm{H}_{2} \text { gas) }\end{array}$ & $\begin{array}{c}49 \\
\text { (absolute) }\end{array}$ & $\mathrm{Y}$ & 4.4 & & 54 \\
\hline 12 & MOF-5: $\mathrm{H}_{2} \rightleftharpoons$ MOF-5 $+\mathrm{H}_{2}^{c}$ & $\begin{array}{l}7.1 \text { (surface excess) } \\
10 \text { (absolute, } \\
\text { incl. } \mathrm{H}_{2} \text { gas) }\end{array}$ & $\begin{array}{c}66 \\
\text { (absolute) }\end{array}$ & Y & 3.8 & & 91,109 \\
\hline
\end{tabular}

prominent complex hydrides include lithium borohydride $\left(\mathrm{LiBH}_{4}\right)$, sodium alanate $\left(\mathrm{NaAlH}_{4}\right)$ and lithium amide $\left(\mathrm{LiNH}_{2}\right)$. Such materials typically liberate hydrogen (or ammonia for amides) endothermically. Stemming from their high hydrogen content by both weight and volume, complex hydrides have attracted great interest in the field of hydrogen storage. For example, $\mathrm{LiBH}_{4}$ has a theoretical gravimetric and volumetric hydrogen capacity of $18.5 \mathrm{wt} \% \mathrm{H}_{2}$ and $120 \mathrm{~g} \mathrm{H}_{2} / \mathrm{L}$, respectively.

Although complex hydrides have been known for an extended time, for example the first report of a pure alkali metal borohydride was in $1940,{ }^{34}$ they were initially not considered for reversible hydrogen storage. This lack of initial interest can be traced to their apparent irreversibility - the inability to both release and take-up hydrogen over many cycles - due to unfavorable hydrogen reaction thermodynamics and/or their slow kinetics. These perceived limitations were challenged in 1996 with the demonstration of reversible hydrogen storage in $\mathrm{NaAlH}_{4}$ at moderate conditions upon the addition of a titanium-based catalyst. ${ }^{32}$ This result re-ignited interest in complex hydrides. Over the last decade several novel approaches for improving the thermodynamic and/or kinetic properties of various complex hydrides have been explored. Notable examples include: "destabilized" reactions, ${ }^{35-38}$ catalyzed reactions (e.g. $\mathrm{TiCl}_{3}$-doped $\left.\mathrm{NaAlH}_{4}\right),{ }^{39,40}$ and discovery of new complex hydride reactants $\left(\text { e.g. } \mathrm{Li}_{4}\left(\mathrm{NH}_{2}\right)_{3}\left(\mathrm{BH}_{4}\right)\right)^{41,42}$ and products (e.g. $\left.\mathrm{Li}_{2} \mathrm{Mg}(\mathrm{NH})_{2}\right){ }^{43}$ These strategies will be presented and discussed in more detail in section V. Fig. 1 (column 2) provides a summary of the key properties of "typical" complex hydrides. Likewise, reactions 4-8 in Table 2 illustrate a few prototypical storage reactions based on complex hydrides. More detailed reviews of the properties of complex hydrides are available elsewhere. ${ }^{44,45}$

\section{Sorbents}

Another approach to hydrogen storage utilizes porous lightweight materials (sorbents) with high surface areas. The interaction between hydrogen and most sorbents involves molecular hydrogen $\left(\mathrm{H}_{2}\right)$ and can therefore be described as a (weak) physisorptive attraction. In addition, the amount of hydrogen adsorbed is typically proportional to the sorbent's surface area. There are a wide range of candidate high surface area (SA) materials having dramatically different physical and chemical properties. In particular, there are two general types of sorbents which have quickly emerged as the front-runners for hydrogen storage: carbon-based materials and metalorganic frameworks (MOFs).

Carbon-based sorbents, synthesized from various organic precursors, can be structured into a variety of forms including: carbon nanotubes, ${ }^{46-48}$ fibers, ${ }^{46,48}$ fullerenes, ${ }^{48,49}$ and activated carbons. ${ }^{50,51}$ This breadth of structural and synthetic diversity enables composition, surface area, and pore size and shape, to be tuned for hydrogen gas uptake.

Metal-organic frameworks (MOFs) are highly porous, crystalline solids constructed from a periodic array of metal clusters linked through multi-topic organic struts. ${ }^{52,53}$ Given the vast number of potential building blocks (i.e. metal clusters and organic linkers), relatively simple synthesis and characterization, and recent progress in increasing surface areas (as high as $5500 \mathrm{~m}^{2} / \mathrm{g}$ ), ${ }^{54}$ MOFs have become an alluring research topic. ${ }^{55-57}$ This building block approach to solidstate chemistry has also incited the creation of other new families of similar highly porous, crystalline materials such as zeolitic imidazolate frameworks $(\mathrm{ZIFs})^{58}$ and covalent organic frameworks (COFs). ${ }^{59}$

Both carbon- and MOF-based sorbents are attractive materials for hydrogen storage, as they have the potential to 
be low cost, are lightweight (translating to favorable gravimetric capacity), reversible, and possess facile hydrogen discharge (charge) kinetics. See Fig. 1 (column 3) and reactions 11 and 12 of Table 2 for the respective sorbent systems summary and example storage data.

In spite of the advantages mentioned above, all sorbents generally share a common limitation - the weak van der Waals interaction between molecular hydrogen and the sorbent (on the order of 1 to $10 \mathrm{~kJ} / \mathrm{mol} \mathrm{H}_{2}$ for most sorbents) - translates to an operating temperature at or near that of liquid nitrogen $\left(-196{ }^{\circ} \mathrm{C}\right)$. Therefore, unlike complex hydrides where the aim is often to lower the hydrogen binding energy (and hydrogen release temperature), with sorbents the goal is to identify strategies to increase the strength of hydrogen binding to greater than $\sim 15 \mathrm{~kJ} / \mathrm{mol} \mathrm{H}_{2}$. Such strategies aimed at realizing ideal hydrogen binding in sorbents include doping (e.g. boron doped carbons), ${ }^{60}$ chemical surface modifications (e.g. open metal sites in MOFs), ${ }^{61}$ and optimizing pore aperture, size and shape. Additionally, due to low materials densities, sorbent systems generally possess moderate hydrogen capacities by volume. See ref. 62 for a comprehensive listing of observed volumetric capacities for MOFs.

One noteworthy approach toward achieving enhanced hydrogen binding in sorbents involves addition of a small amount of hydrogen dissociation catalyst (e.g. Pd or Pt) along with a carbon-based bridging substance. These additions are key components in the so-called "spillover" of atomic hydrogen into MOF- or carbon-based sorbents. ${ }^{63}$ While the specific nature and mechanism of spillover is not yet definitively understood, reversible room-temperature uptake and release have been reported in spillover systems. ${ }^{63}$ Further information regarding the properties of sorbents for hydrogen storage (via physisorption or spillover) can be found elsewhere. ${ }^{62,64-66}$

\section{Chemical hydrides}

The fourth and final class of hydrogen storage materials are the so-called "chemical hydrides." Similar to complex hydrides, these compouds can contain large quantities of hydrogen by mass and volume. They can appear in either solid or liquid form, and can be heated directly, passed through a catalyst-containing reactor, or combined with water (i.e. hydrolysis) or other reactants to produce hydrogen. Unlike reversible complex hydrides, however, chemical hydrides are intended as "one-way" single-use fuels: The left-over byproduct (spent material) must be removed from the vehicle for off-board regeneration. A few prominent examples of chemical hydride reactions include thermal decomposition of ammonia borane $\left(\mathrm{NH}_{3} \mathrm{BH}_{3}\right),{ }^{67}$ hydrolysis of sodium borohydride $\left(\mathrm{NaBH}_{4}\right),{ }^{68,69}$ and off-board reversible liquid organic carriers (e.g. $N$-ethyl carbazole) ${ }^{70}$ The appeal of some chemical hydrides originates from their high gravimetric and volumetric capacities and near-ambient operating conditions which are often less than $80{ }^{\circ} \mathrm{C}$ (at $0.1 \mathrm{MPa}$ hydrogen pressure). See Fig. 1, column 4 for a summary of chemical hydride properties. For example, ammonia borane $\left(\mathrm{NH}_{3} \mathrm{BH}_{3}\right)$ contains over 19 wt $\% \mathrm{H}_{2}$ and $150 \mathrm{~g} \mathrm{H}_{2} / \mathrm{L}$ of hydrogen by weight and volume respectively (materials basis) and practically releases over one equivalent of $\mathrm{H}_{2}$ rapidly at
$70{ }^{\circ} \mathrm{C}$ using a transition metal catalyst. ${ }^{71}$ Likewise, materials related to ammonia borane, for example ammonia triborane $\left(\mathrm{NH}_{3} \mathrm{~B}_{3} \mathrm{H}_{7}\right){ }^{72}$ are being actively pursued as candidate hydrogen storage materials. See reactions $10 \mathrm{a}$ and $10 \mathrm{~b}$ of Table 2 for ammonia borane reaction data.

While chemical hydrides are capable of operating within temperature-pressure conditions which exist onboard FC vehicles (i.e. utilizing fuel cell waste heat), they suffer from a few drawbacks which could limit their practicality. In particular, many chemical hydride reactions are exothermic and can result in the formation of very stable dehydrogenated products (e.g. the hydrolysis of $\mathrm{NaBH}_{4}$ results in the formation of $\mathrm{NaBO}_{2}$ ). Thus, the reconstitution of these stable products back into the hydrogen-containing fuel generally involves energy-intensive reaction steps, for example $\mathrm{B}-\mathrm{N}$ or $\mathrm{B}-\mathrm{O}$ bond breaking reactions, which contribute to an overall energy inefficient process. This, coupled with complex fuel system components that are often high-cost, such as dehydrogenation reactors, multiple (compartment) tanks, phase separators, and pumps for addition (removal) of fuel (spent material), complicates the implementation of chemical hydrides as onboard storage media. In fact, these cumulative challenges have contributed to a recent discontinuation (no-go decision) of research on hydrolysis of sodium borohydride by the DOE. ${ }^{73}$ Nevertheless, the positive attributes - high capacity and near ambient operation - make many chemical hydrides compelling candidates for hydrogen storage. More detailed reviews of the properties of chemicals hydrides, with an emphasis on ammonia borane, are available elsewhere. ${ }^{74,75}$

\section{Materials synthesis and processing}

Of course, for any material in the above four classes to form part of a practical hydrogen storage system, techniques must be available to synthesize and process the material. These techniques may only exist on a laboratory scale for research purposes, but ultimately must be capable of low-cost scaling to large volumes for a commercial vehicle application.

Synthesizing refers to the process of producing a material, while processing is the act of modifying a material to improve its properties (e.g., kinetic and/or thermodynamic properties). There are a variety of techniques available for both synthesis and processing. Metallurgical techniques are commonly used to synthesize conventional metal hydrides, whereas chemical reaction routes are used in the production of complex hydrides, chemical hydrides, and a sub-set of sorbent materials such as MOFs. Processing methods range from simple techniques such as heat treatment (to homogenize composition and microstructure) and cyclic evacuation/hydriding (activation), to more complex operations such as thin film deposition, sol-gel processing, and high energy mechanical ball milling (alloying). Scaffolding, a technique relatively new to the field of hydrogen storage, involves the deposition of a storage material within the (nano-sized) pores of a host scaffold material. ${ }^{76,77}$

High-throughput materials screening, a promising technique commonly used in the pharmaceutical industry, couples the steps of synthesis, processing, and characterization to accelerate the discovery of hydrogen storage materials. ${ }^{78,79}$ 


\section{Materials attributes and methods for their evaluation}

As outlined in section II, for transportation applications a critical goal is to develop a hydrogen storage technique able to contain enough hydrogen fuel to enable a conventional driving range within the constraints of weight, volume, driving dynamics, efficiency, safety, durability, and cost typical of modern vehicles. These vehicle restrictions provide a bounded description of the required fuel system metrics. In turn, the fuel system attributes are intimately tied to the properties of the hydrogen storage material, such as capacity, thermodynamics, and kinetics. In the sections that follow we provide a detailed description of the materials properties (capacity, thermodynamics, and kinetics) that strongly impact system performance.

\section{Capacity}

Hydrogen capacity can be defined as the amount of hydrogen stored per unit weight (gravimetric capacity) or volume (volumetric capacity). Alternatively, given the lower heating value of hydrogen, $120.2 \mathrm{MJ} / \mathrm{kg}$, gravimetric and volumetric capacities can be expressed in terms of the chemical energy of stored hydrogen. Importantly, there are multiple classifications of capacity which have appeared in the literature, depending on the context. In this section the following types of commonly-discussed capacities are defined: materials- or system-based capacity, reversible capacity, usable capacity, excess capacity, and absolute capacity.

Fig. 2 summarizes the differences between the different types of storage capacities. Capacity can be reported at the materials level, where it is defined as the ratio of hydrogen mass stored to the (total) mass or volume of storage material. In a vehicle context, capacity is reported on a system level. This takes into account the weight and volume of all of the ancillary fuel system components, often referred to as the balance of plant (BOP), which includes: the vessel for material containment, hydrogen fuel, thermal management equipment, pressure regulators, valves, piping, sensors, safety components, mounting brackets, etc. The system-based capacity is an upper limit to the amount of useable hydrogen (Fig. 2, black line). In particular, there will most likely be hydrogen left in the tank due to a minimum delivery pressure limit mandated for proper fuel cell operation (0.3 MPa, Ultimate target, designated as $P_{\min }$ in Fig. 2). This low-pressure or "unusable" hydrogen (Fig. 2, red line) must be excluded from the useable capacity.

As an example of capacity in practical system environment, Ti-catalyzed $\mathrm{NaAlH}_{4}$ has a gravimetric capacity (materialsbasis) of approximately $3.7 \mathrm{wt} \% \mathrm{H}_{2}$ for the first desorption step (reaction (4a) in Table 2). ${ }^{32}$ However, when the material is processed and incorporated into an optimized onboard system, the projected gravimetric capacity drops to almost half that value (e.g. $2.0 \mathrm{wt} \% \mathrm{H}_{2}$ for the first-step). ${ }^{80}$ For comparison, the Ultimate DOE gravimetric capacity target (useable system-basis) is $7.5 \mathrm{wt} \% \mathrm{H}_{2}$. Given that each candidate material will have distinct engineering properties (packing density, thermal conductivity, etc.), it is difficult to predict capacities on a system level without rigorous systems
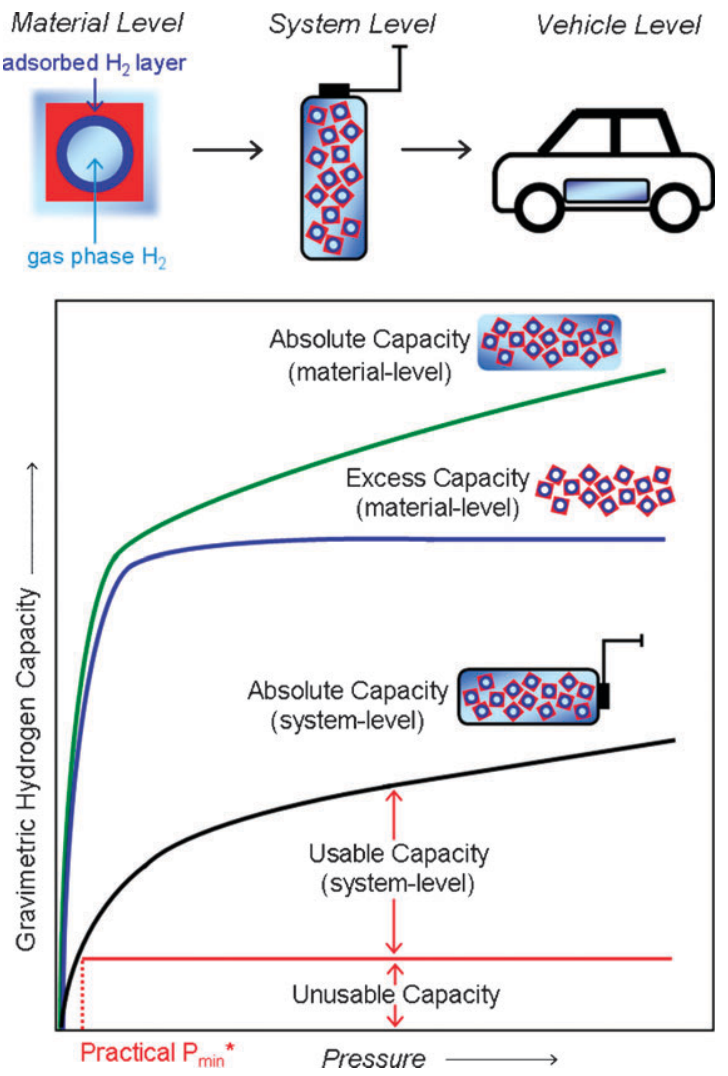

Fig. 2 Graphical representation of various types of gravimetric capacity versus pressure (at a given temperature) on both the materials and system level. While the present depiction focuses on a sorbentbased system, these forms of capacity can be more generally applied to the other materials categories.

modeling. For this reason, most studies report capacities on a materials-basis.

\section{Gravimetric capacity}

Gravimetric capacity of hydrogen storage materials can be experimentally determined using either gravimetric or volumetric methods. Both methods indirectly calculate hydrogen capacity based on the change in a measurable property such as pressure (volumetric method) or weight (gravimetric method). Like many experimental methods, the soundness of calibrations, testing protocol, instrument, and data corrections impact the accuracy and precision of the data. For example, both gravimetric and volumetric methods rely on the assumption that only hydrogen gas is being released. Unfortunately, this assumption is not always valid, and other volatile byproducts such as ammonia $\left(\mathrm{NH}_{3}\right)$, diborane $\left(\mathrm{B}_{2} \mathrm{H}_{6}\right)$, or water $\left(\mathrm{H}_{2} \mathrm{O}\right)$ can be liberated from the material during the measurement. These non-hydrogen gases affect pressure and weight and thus distort the hydrogen capacity data. One recommended review that details hydrogen storage measurement methods provides common metrics and 'best practices' for measuring and reporting practical hydrogen storage properties. ${ }^{81}$

Calculating gravimetric density using the volumetric method (also known as Sievert's method) relies on temperature-pressure-volume correlations to determine 
hydrogen concentration. In particular, the hydrogen uptake (release) is monitored by the drop (rise) in hydrogen pressure in a system of known volume, temperature, and sample mass. Of the several necessary considerations and corrections to raw data (e.g. involving temperature, volume, compressibility, reverse Joule-Thompson heating, sample size, etc.), ${ }^{81,82}$ the most important for the volumetric method is the temperature correction. In particular, the volumetric method requires knowledge of the exact temperature spanning the sample cell, gas reservoir, and manifold connecting them. Unfortunately, thermal gradients exist between the sample cell, which can experience temperatures ranging from -196 to $500{ }^{\circ} \mathrm{C}$, and the remainder of the apparatus. As an example, cryogenic data collection for a given sorbent might involve placing the sample cell at $-196{ }^{\circ} \mathrm{C}$ while the gas reservoir (and lines connecting the former) remain at ambient temperature. When an aliquot of ambient-temperature gas is introduced into the cryogenic sample cell, a reduction in gas pressure occurs as the gas cools. Since a volumetric device correlates a pressure decrease to gas uptake by the sample, a fictitious uptake would be recorded. Such thermal gradients are therefore accounted for via an empirically-determined correction factor. These correction factors are typically determined under identical pressuretemperature-volume conditions via comparison with nonporous materials that exhibit negligible hydrogen uptake. ${ }^{81}$

In the gravimetric method, hydrogen uptake is measured by monitoring the weight change of the sample following a step change in hydrogen pressure. Most apparatus based on this method utilize a highly sensitive microbalance where the apparent weight of the unhydrided sample is used as a counterbalance. During a sorption measurement, hydrogen from an external source enters the evacuated sample cell where it is taken up by the sample material. The instrument monitors the weight change along with pressure and temperature to quantify the hydrogen uptake. The most important correction for gravimetry is buoyancy from the sample and sample container. The effect of buoyancy arises from the displacement of hydrogen gas by the sample and sample container, resulting in an upward force on the sample. The degree of the upward force (buoyancy) is proportional to the volume of hydrogen displaced, and the density of the surrounding hydrogen at the measurement temperature and pressure. $^{83}$

Empirical data should be compared with that which is expected based on the composition and structure of the material. Theoretical gravimetric hydrogen capacity (materials basis) is generally easily calculated for complex, conventional, and chemical hydrides if the composition of the starting materials and products of the hydrogen release reaction are known. For example, one mol of $\mathrm{LiBH}_{4}$ decomposes into $\mathrm{LiH}+\mathrm{B}$, producing $3 / 2$ moles $\mathrm{H}_{2}$. Thus, the expected gravimetric capacity is simply taken as the percent mass ratio of amount of hydrogen released $\left(3 / 2 \mathrm{H}_{2}\right.$ or $\left.3 \mathrm{~g}\right)$ and the amount of initial material $\left(1 \mathrm{LiBH}_{4}\right.$ or $\left.21.8 \mathrm{~g}\right)$ which is approximately $14 \mathrm{wt} \% \mathrm{H}_{2}$.

For sorbent systems, hydrogen that is directly adsorbed on the surface of the sorbent is referred to as excess capacity $N_{\mathrm{ex}}$, (Fig. 2, blue line in bottom panel); this adsorbed hydrogen is represented as a dark blue layer on the surface of the material (depicted with red coloring in Fig. 2, top). ${ }^{84}$ The maximum expected excess capacity can be estimated by assuming that hydrogen adsorbs as a monolayer on the sorbent with a density equal to that of liquid hydrogen. ${ }^{85}$ Thus, under this approximation, excess capacity is proportional to the sorbent surface area where the proportionality constant is: $2.28 \times$ $10^{-3} \mathrm{wt} \% \mathrm{H}_{2} \mathrm{~m}^{-2} \mathrm{~g}$ (often referred to as the 'Chahine Rule'). ${ }^{86}$ That is, a sorbent possessing a specific surface area of $500 \mathrm{~m}^{2} / \mathrm{g}$ should store up to approximately $1 \mathrm{wt} \%$ hydrogen. Agreement of this surface area verses uptake relationship has been demonstrated for a wide range of sorbents. ${ }^{87}$ Absolute capacity ( $N_{\text {abs }}$, Fig. 2, green line) includes excess capacity in addition to the amount of gas-phase (gp) hydrogen $\left(\rho_{\mathrm{gp}}\right)$ that is not interacting with the sorbent but usually present in the free pore volume ( $\left.V_{\text {pore }}\right)$ (represented as light blue region in Fig. 2, top). Hence:

$$
N_{\mathrm{abs}}=N_{\mathrm{ex}}+\rho_{\mathrm{gp}} V_{\text {pore }}
$$

While the excess capacity is usually that which is obtained through experimental measurements, the absolute capacity is more relevant in the context of vehicular storage, as it includes all hydrogen present in the system.

\section{Volumetric capacity}

Volumetric hydrogen capacity is the amount of hydrogen stored per unit volume (units of $\mathrm{g} \mathrm{H}_{2} / \mathrm{L}$ ). Like gravimetric capacity, volumetric capacity assumes various forms depending on the context: for example materials- or systembased, useable and reversible.

The volumetric density of hydrogen storage materials is typically calculated from the product of the materials-based gravimetric capacity and the density of the hydrogen storage material. The gravimetric capacity is experimentally determined using one of the previously prescribed methods (e.g. volumetric or gravimetric methods). However, the density of the material depends sensitively on its physical form ranging from a maximum for single crystals, to lower values for loose powders with high surface area morphologies. The density value for a given material can radically change based on its physical form. For example, $\mathrm{NaAlH}_{4}$ has a theoretical (single crystal) density of $1.3 \mathrm{~g} / \mathrm{cm}^{3}$ but a powder density of just $0.39 \mathrm{~g} / \mathrm{cm}^{3}{ }^{80}$ Ideally, one should perform measurements using the form of material that is intended for use on-board the vehicle.

The ultimate processed form of the storage media should simultaneously maximize volumetric capacity and hydrogen uptake/release kinetics while minimizing cost and complexity. Unfortunately, often times the density of the specific material used for gravimetric capacity measurements is either undetermined and/or the "optimum" form unknown. Instead, single crystalline (best case) values are typically used to estimate volumetric capacity at the materials discovery stage. While this approximation is instructive for making comparisons at the materials-level, the more-important system-level volumetric capacity is currently poorly characterized and less understood.

\section{Capacity trends for materials classes}

Here we provide an overview of trends for gravimetric and volumetric capacities (materials-level) for each of the four primary classes of hydrogen storage materials. 
Along with ambient temperature-pressure operation, one of the key motivators for pursuing conventional metal hydride storage stems from their exceptional volumetric capacity. These compounds (e.g. $\mathrm{AB}_{2}, \mathrm{AB}_{5}$ and $\mathrm{BCC}$ phases) possess single-crystal densities of approximately 4 to $8 \mathrm{~g} / \mathrm{cm}^{3}$, which enables volumetric capacities up to $170 \mathrm{~g} \mathrm{H}_{2} / \mathrm{L}$ (materials-basis). ${ }^{27,88}$ Unfortunately, current alloy compositions which operate under practical temperature-pressure conditions, for example 0.1 to $1 \mathrm{MPa}$ and 0 to $100{ }^{\circ} \mathrm{C}$, largely involve high- $Z$ metals (e.g. La, Ni, Cr, Fe, Mn, etc.). The use of such heavy elements translates to poor gravimetric capacities, typically $1-3 \quad \mathrm{wt}^{\%} \% \mathrm{H}_{2}$ (materials-basis). Thus, identifying methods to further enhance gravimetric capacity, for example accessing un-utilized interstitial sites for hydrogen binding and/or discovery of lighter-element compositions, remains a challenging research topic for conventional metal hydrides.

Complex hydrides typically exhibit exceptional gravimetric and volumetric capacities stemming from their make-up of low- $Z$ elements (e.g. Li, Mg, B, N, and $\mathrm{Al}$ ), large concentration of hydrogen, and moderate materials densities (e.g. approximately $1.3 \mathrm{~g} / \mathrm{cm}^{3}$ theoretical density of $\left.\mathrm{NaAlH}_{4}\right) .{ }^{80}$ These characteristics serve as key motivators for $\mathrm{R} \& \mathrm{D}$ focused on these compounds. For example, prominent complex hydrides such as $\mathrm{LiBH}_{4}, \mathrm{Mg}\left(\mathrm{BH}_{4}\right)_{2}$, and $\mathrm{NaBH}_{4}$ all contain over $10 \mathrm{wt} \%$ hydrogen. Thus, even in combination with other slightly 'heavier' hydrides or dead-weight kinetic aids (e.g. catalysts, scaffolds, etc.), hydrogen storage systems based on complex hydrides have the potential to far surpass the gravimetric and volumetric capacities of conventional metal hydrides and compressed storage technologies.

As previously discussed, for sorbent systems the excess gravimetric capacity is typically proportional to the specific surface area of the sorbent: at $-196{ }^{\circ} \mathrm{C}$ equal to $1 \mathrm{wt} \% \mathrm{H}_{2}$ per $500 \mathrm{~m}^{2} / \mathrm{g}$ of surface area. Recent research efforts have proven particularly successful for producing high surface area sorbents capable of achieving high gravimetric density. For example, MOF-177 has an apparent Langmuir surface area of $5250 \mathrm{~m}^{2} / \mathrm{g}$ and adsorbs approximately $7.5 \mathrm{wt} \%$ hydrogen at $6 \mathrm{MPa}$ and $-196{ }^{\circ} \mathrm{C} .{ }^{54} \mathrm{In}$ addition to designing high surface area structures, the process of removing all residual solvent molecules (often refered to as 'activation') is also vital for maximizing capacity in a given sorbent.

Demonstrating high volumetric capacity has proven difficult in sorbent systems. This challenge originates from the porous nature of the compounds, and often translates into low materials densities. Taking the previous example, MOF-177 has an accessible pore volume of $1.7 \mathrm{~cm}^{3} / \mathrm{g}$ and crystallographic density of just $0.427 \mathrm{~g} / \mathrm{cm}^{3} .{ }^{89}$ This translates to a bestcase excess volumetric uptake of approximately $32 \mathrm{~g} \mathrm{H}_{2} / \mathrm{L}$ or $49 \mathrm{~g} \mathrm{H}_{2} / \mathrm{L}$ for absolute volumetric uptake (same conditions as above). MOF-5, which has a slightly higher crystallographic density of $0.61 \mathrm{~g} / \mathrm{cm}^{3},{ }^{90}$ has best-case excess or absolute volumetric capacities of up to 42 or $66 \mathrm{~g} \mathrm{H}_{2} / \mathrm{L}$, respectively (based on anhydrous sythesis methods). ${ }^{91}$ Therefore, in order to improve volumetric capacity one must either increase hydrogen uptake or increase the material density, without compromising surface area.

Like complex hydrides, chemical hydrides typically afford high gravimetric capacities (materials-basis). Additionally, chemical hydrides such as $\mathrm{NH}_{3} \mathrm{BH}_{3}$ possess modest volumetric capacities, particularly if the material can be compacted (e.g. into a tablet). For example, at a temperature of approximately $150{ }^{\circ} \mathrm{C}$ (at $0.1 \mathrm{MPa}$ ), two hydrogen equivalents or $13 \mathrm{wt} \% \mathrm{H}_{2}$ can be released from $\mathrm{NH}_{3} \mathrm{BH}_{3}$ via thermolysis. ${ }^{92,93}$ If the material is implemented as a loose powder (worst-case) the anticipated volumetric capacity (materials-basis) would reach $40 \mathrm{~g} \mathrm{H}_{2} / \mathrm{L}$, whereas if the material was sufficiently compacted, volumetric capacities closer to $60 \mathrm{~g} \mathrm{H}_{2} / \mathrm{L}$ could be possible. $^{92}$

Also belonging to the so-called chemical hydride category are liquid organic carriers such as $N$-ethylcarbazole and decalin which are traditionally composed of carbon, hydrogen, along with other heteroatoms (e.g. nitrogen). Given the hydrocarbon base structure, the current gravimetric capacity is somewhat limited to removal of one hydrogen per $-\mathrm{CH}_{2}$ unit (or $7.1 \mathrm{wt} \% \mathrm{H}_{2}$ ). Neglecting the identification of novel chemistries which could surpass this limit, the burden of optimizing the gravimetric capacity would fall on reducing the BOP weight. Nevertheless, these liquid carriers possess relatively high volumetric density, $54 \mathrm{~g} \mathrm{H}_{2} / \mathrm{L}$ for $N$-ethylcarbazole, ${ }^{70}$ and likewise would be favorable from refueling and infrastructure perspectives.

\section{Thermodynamics}

The thermodynamics of the hydrogen storage reaction is one of the most fundamental properties of a hydrogen storage material. Thermodynamic factors dictate the equilibrium relationship between the operating temperature and pressure, and therefore influence whether the pressure of desorbed hydrogen is sufficient to supply a fuel cell. The heat requirements for desorption and the potential for on-board recharge (or "reversibility") are also tied to the thermodynamic properties of the storage reaction.

Equilibrium between gas phase hydrogen and one or more condensed phases is described by the van't Hoff equation:

$$
P_{\mathrm{H}_{2}}=P_{0} \exp \left(\frac{-\Delta H}{R T}+\frac{\Delta S}{R}\right)
$$

where $P_{\mathrm{H}_{2}}$ is the equilibrium pressure, $P_{0}$ is a reference pressure (typically atmospheric pressure), $R$ is the gas constant, $T$ is the absolute temperature, and $\Delta H$ and $\Delta S$ give the change in enthalpy and entropy, respectively, accompanying the hydrogen storage reaction. While the van't Hoff equation is applicable generally to systems involving equilibrium between gas and condensed phase(s), it is conventional to use alternative expressions, such as the Clausius-Claperon or Dubinin-Astakhov equation, to describe $\mathrm{H}_{2}$ uptake in sorbent materials. ${ }^{94}$ We adopt a sign convention such that a reaction which releases hydrogen endothermically will have $\Delta H>0$.

\section{Optimal reaction enthalpy}

Given the targeted pressures and temperatures described in Table 1, it is possible to identify a range of reaction enthalpies that satisfy these conditions through application of the van't Hoff equation. This approach translates vehicle operating constraints into thermodynamic constraints which can be used to guide materials development. The enthalpy also conveys the 
quantity of heat that must be added to (or subtracted from) the system during hydrogen release (or uptake). For example, materials having large enthalpies of desorption are undesirable since they require high temperatures for hydrogen release and will liberate a large amount of heat upon rehydriding (see Fig. 5 and subsequent discussion of Efficiency). On the other hand, a system with a small desorption enthalpy, although in principle capable of liberating hydrogen at low temperatures, will require extremely high pressures to recharge. Hence the enthalpy is both a useful materials property and an important engineering design parameter.

Assuming a fixed temperature of $80{ }^{\circ} \mathrm{C}$, Fig. $3^{110}$ plots the equilibrium hydrogen pressure $P_{\mathrm{H}_{2}}$ as a function of reaction enthalpy $\Delta H$ for several plausible reaction entropies. ${ }^{11}$ At an equilibrium pressure of $0.3 \mathrm{MPa}$ - equal to the Ultimate target for minimum $\mathrm{H}_{2}$ pressure delivered to the fuel cell (Table 1)a desorption reaction with the "maximum" entropy change yields a desorption enthalpy of $48 \mathrm{~kJ} / \mathrm{mol} \mathrm{H}_{2}$. Conversely, an enthalpy of $17 \mathrm{~kJ} / \mathrm{mol} \mathrm{H}_{2}$ is required for recharge under $35 \mathrm{MPa}$ assuming a "minimum" entropy change. Based on these two operating extremes it is possible to identify a "thermodynamically ideal" enthalpy range of approximately 20-50 kJ/mol H $\mathrm{H}_{2}$. However, as we will show below, efficiency considerations suggest that targeting the lower third of this range $\left(20-30 \mathrm{~kJ} / \mathrm{mol} \mathrm{H}_{2}\right)$ is optimal. A summary of the enthalpic properties of several hydrogen storage materials of recent interest is given in Table 2 .

\section{Altering thermodynamics: destabilization and nanosizing}

Until recently it was generally perceived that the only way to alter the thermodynamics of a hydrogen storage reaction was to change the composition, and hence the identity, of the storage material itself. However, recent work involving "destabilized" mixtures of hydrides and the nanoscale processing of known hydrides has altered this perception.

Destabilization refers to the process of lowering the effective enthalpy of a hydrogen desorption reaction, which, when un-modified would exhibit a $\Delta H$ which is too large (i.e., $\Delta H>$ $50 \mathrm{~kJ} / \mathrm{mol} \mathrm{H}_{2}$ ), or too "stable," for practical applications. Although the destabilization concept dates to the $1960 \mathrm{~s},{ }^{36}$ it was only recently "rediscovered" in mixtures of $\mathrm{LiBH}_{4}$ and $\mathrm{MgH}_{2}:{ }^{35} \mathrm{LiBH}_{4}+\frac{1}{2} \mathrm{MgH}_{2} \rightleftharpoons \mathrm{LiH}+\frac{1}{2} \mathrm{MgB}_{2}+2 \mathrm{H}_{2}$. In this case the effective enthalpy of the combined reaction $(\Delta H=$ $41 \mathrm{~kJ} / \mathrm{mol} \mathrm{H}_{2}$ ) was decreased below those of the isolated, stable compounds (each with $\Delta H>60 \mathrm{~kJ} / \mathrm{mol} \mathrm{H}_{2}$ ) due to the exothermic formation enthalpy of the stable product $\mathrm{MgB}_{2}$. In this case destabilization occurs by lowering the enthalpy of the product phases; a similar destabilizing effect can be achieved by raising the enthalpy of the reactants. Many other promising destabilized reactions have since been proposed by theory $^{37,99,122,123}$ and examined by experiment. ${ }^{35,38,40}$

Another potential avenue for altering thermodynamics is via extreme reduction in particle size. As mentioned above, ball milling is one of the techniques commonly used to reduce the particle size of hydride powders. (For example, particle sizes typically achieved by milling $\mathrm{NaAlH}_{4}$ are on the order of nanometers.) While small particles are known to increase the kinetics of the storage reaction, in general they have not been associated with a change in thermodynamics. However, a recent quantum-chemical study ${ }^{12}$ demonstrated that the desorption temperature for very small $(d \sim 1.3 \mathrm{~nm})$ particles of $\mathrm{MgH}_{2}$ could be decreased by approximately $100{ }^{\circ} \mathrm{C}$ below the bulk desorption temperature. The effect was attributed to a more rapid destabilization of $\mathrm{MgH}_{2}$ with respect to particle size than in bulk Mg. This approach, if able to be realized experimentally, has the potential to impact both the kinetics and thermodynamics of the storage reaction.

\section{Methods for thermodynamic assessment}

Although thermodynamic data are available for many of the conventional (binary) metal hydrides, reliable data for the complex hydrides, chemical hydrides, and sorbent systems are much harder to come by. This dearth of information is partially a consequence of the novelty of these compounds, but also reflects the difficulties associated with analyzing systems having slow kinetics and/or complex reaction mechanisms. Despite these complications, the importance of thermodynamics on the performance of a storage material suggests that it is imperative that reliable techniques exist for the assessment of thermodynamic quantities. Below we briefly

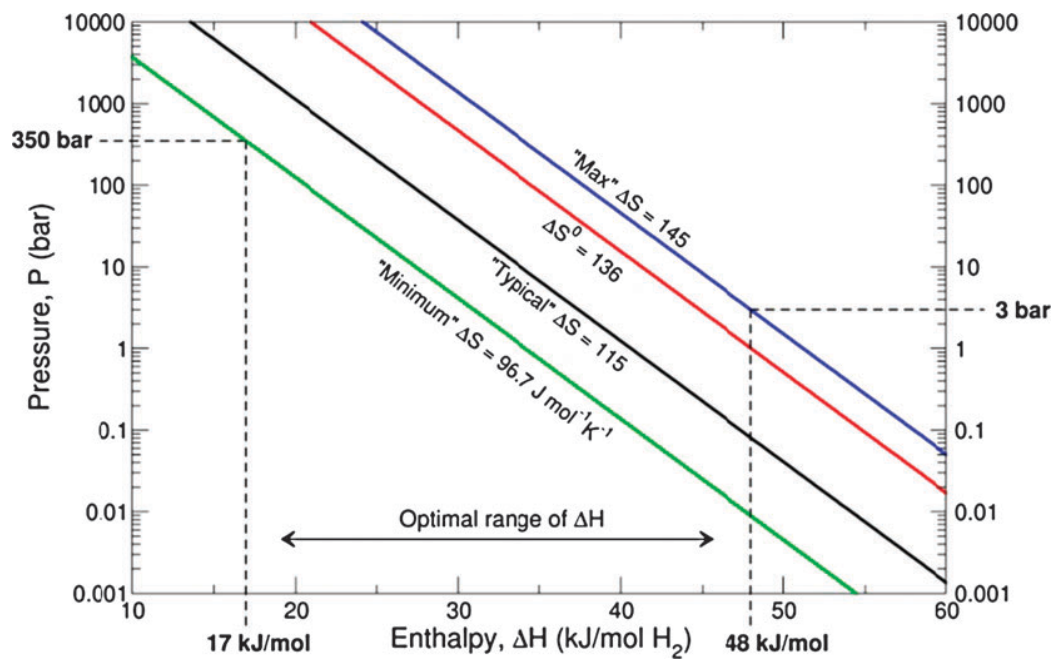

Fig. 3 Equilibrium $\mathrm{H}_{2}$ desorption pressure $(P)$ as a function of desorption enthalpy $(\Delta H)$ for various choices of desorption entropy $(\Delta S) .{ }^{10}$ 
describe the most commonly-used experimental and computational techniques for measuring these properties. More detailed information regarding these techniques can be found elsewhere. ${ }^{81,113}$

Experimental techniques. Experimentally, the most common method for determining $\Delta H$ and $\Delta S$ values relies on equilibrium pressure-composition-temperature (PCT) data obtained via one of the previously discussed volumetric or gravimetric measurement methods (in this context 'composition' refers to the concentration of hydrogen in the sample $\left(e . g\right.$. $\left.\left.\mathrm{wt}_{\mathrm{H}} \mathrm{H}_{2}\right)\right)$. The procedure involves a series of experiments which are illustrated schematically in Fig. 4. Beginning with desorption ${ }^{114}$ from a charged sample, an individual PC curve is first generated at a fixed temperature, $T_{2}$. This involves perturbing the sample from equilibrium by applying a small step-change reduction in pressure and allowing equilibrium to subsequently be re-established (see the upper left portion of the pathway traced in Fig. 4(a) culminating in the filled equilibrium datapoint at capacity $C_{1}$ ). An alternative depiction of this process, now described in terms of pressure and capacity, is shown in Fig. 4(b) (note that in this representation the desorption pathway begins at the top-right portion of the plot). At a certain point within the desorption process the system will enter the so-called "plateau region," where the equilibrium pressure will remain (mostly) constant at the plateau pressure $\left(P_{\text {eq }}\right)$ over a range of compositions, which in our example include compositions $C_{1}$ through $C_{3}$. Depending on the kinetics of hydrogen uptake/release, re-equilibration can take from a few minutes up to several weeks. Once the sample reaches equilibrium, a single PC data point is recorded. Maintaining temperature, the pressure is again decreased in a step-wise fashion and additional equilibrium $\mathrm{PC}$ points are collected (e.g. $C_{2}$ and $C_{3}$ ) until a full PC isotherm (PCI) is defined (Fig. 4(b), lower curve). It is important to ensure that each point of the PCI curve represents an equilibrium state in order to avoid an artificial shortening or sloping of the plateau pressure $\left(P_{\text {eq }}\right)$ region, or large absorption/desorption hysteresis. Finally, several similar PCI (also called PCT) curves are collected at different temperatures $T_{1}-T_{4}$ (Fig. 4(c)), and the natural log of plateau pressure $\left(\ln P_{\text {eq }}\right)$ for each isotherm is plotted against reciprocal temperature $(1 / T)$. Based on the van't Hoff equation, $\Delta H$ and $\Delta S$ can be extracted from the slope and $y$-intercept of this linear plot (Fig. 4(d)).

Two phenomena of PCT curves which have practical implications are hysteresis and sloping of the plateau region. Hysteresis is exemplified by the absorption plateau $\left(P_{\text {eq, }}\right)$ being located at higher pressure than the desorption plateau $\left(P_{\text {eq,D }}\right)$ [i.e. adsorption $P_{\text {eq, }}>$ desorption $P_{\text {eq,D }}$ as shown in Fig. 4(b)]. Thus, there are two sets of thermodynamic parameters that can be extracted, one for each plateau. Often times $P_{\text {eq,D }}$ is assumed to be the "true" equilibrium, although an alternative viewpoint that the equilibrium lies somewhere between $P_{\text {eq,A }}$ and $P_{\text {eq,D }}$ has also been suggested. ${ }^{115,116}$

The observance of hysteresis is related to the interaction between hydrogen and materials, and depends on a sample's history and test procedure. ${ }^{25}$ For practical on-board vehicular applications, hysteresis will increase the required service (recharge) pressure. Thus, it is desirable that the magnitude of hysteresis be as small as possible.

A second feature common to real PCT curves is plateau sloping, which can be assessed by the relation, slope $=$ $\mathrm{d}(\ln P) / \mathrm{d}\left(\mathrm{wt}_{\mathrm{t}} \% \mathrm{H}_{2}\right)$. Sloping originates from compositional inhomogeneities ${ }^{117}$ which can often be mitigated by processing methods that aid in the creation of a homogeneous sample, such as heat treatment or milling. The practical impact of plateau sloping is a reduction in reversible capacity, defined by the width of the plateau region. That is, the amount of hydrogen to be extracted (introduced) is dependent on the on-board operation pressure range. Significant plateau sloping results in a reduction in the amount of hydrogen accessible in the prescribed operating pressure window.

Another commonly-used method for experimentally determining thermodynamic properties is differential scanning calorimetry (DSC). DSC is a thermal analysis technique that measures the heat flow difference into a sample and a reference material as a function of temperature during a controlledtemperature program. ${ }^{116}$ The benefits of DSC include: short measurement times (on the order of hours), small sample sizes ( $\sim-10 \mathrm{mg}$ ), and data variety (e.g. thermodynamic, kinetic or thermal information). In regards to hydrogen storage materials characterization, DSC is typically used for obtaining enthalpy data for both hydrogen storage reactions and for other physio-chemical events, such as melting or polymorphic transformations. During a DSC measurement, the reference and sample sensors detect a constant increase in temperature versus time as specified by the heating program (e.g. $5 \mathrm{~K} / \mathrm{min}$ ). When a thermal event occurs, for example endothermic hydrogen release from a material, the heat flux provided to the sample is increased to maintain the temperature of sample constant while the reference temperature continues to increase linearly according to the temperature program. Once the hydrogen release event is complete, the increased heat flux in the sample will resume sample temperature to the same linear increase as the reference cell. The area under the sample signal curve is proportional to the amount of heat consumed for that event, and can be related to $\Delta H$.

While DSC measurements are often used for directly reporting the enthalpy values of hydrogen storage reactions, the process of extracting accurate information is often complicated by the multi-phase nature of the reaction, which can involve simultaneous heat and mass transfer (release/uptake of $\mathrm{H}_{2}$ gas) events. Thus, the following factors should be considered to ensure data robustness: (a) air-free sample loading, (b) accurate sample mass, crucible type, heating rate, and gas atmosphere, (c) accurate temperature and sensitivity calibrations, and (d) baseline corrections (see ref. 116 for additional details and examples).

Computational techniques. Recent advances in computational algorithms and computer hardware have made it possible to calculate the thermodynamic properties of hydrogen storage reactions with an accuracy approaching that of experiments. While at present computation cannot eliminate the need for experiment, the efficiency and predictive power of computation affords significant advantages in the search for new hydrogen storage materials. 

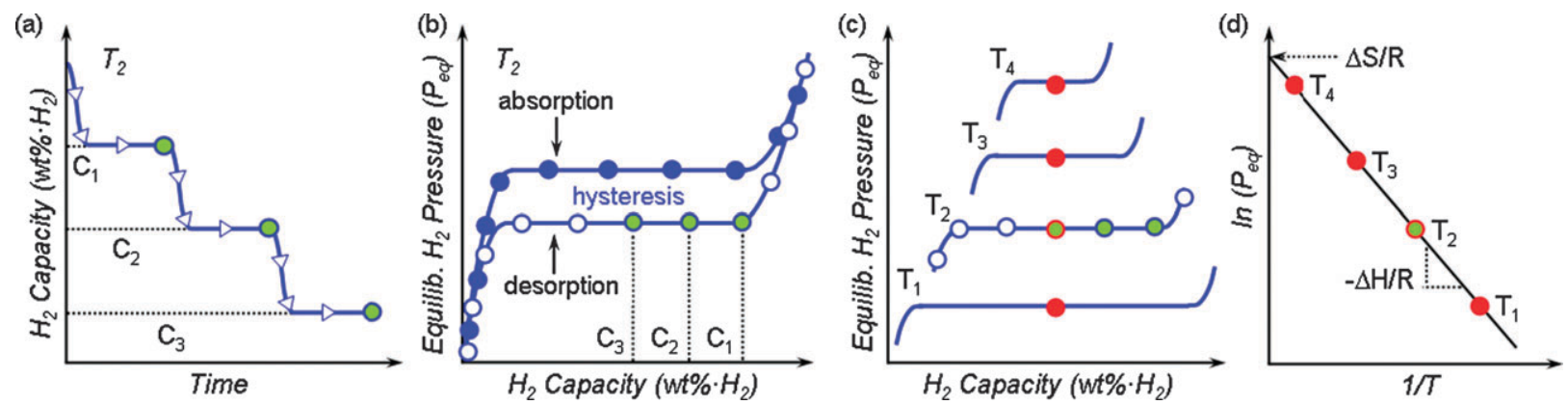

Fig. 4 Schematic summarizing the experimental determination of thermodynamic properties using pressure-composition isotherms. Step (a): determination of a series of equilibrium concentration points $\left(C_{1}, C_{2}\right.$ and $\left.C_{3}\right)$ at a given temperature via the step-wise perturbation of pressure (selected points along a desorption isotherm depicted); (b): construction of a full PCT curve from the series of kinetic measurements in (a) including a characteristic hysteresis loop; (c): collection of analogous desorption PC isotherms at different temperatures $\left(T_{1}\right.$ to $\left.T_{4}\right)$ with the flat plateau pressures designated by the filled red points; and (d): creation of the van't Hoff plot, where the slope and intercept of the line are related to the enthalpy $(\Delta H)$ and entropy $(\Delta S)$ of reaction, respectively.

As the vast majority of candidate storage materials are crystalline compounds, most computational studies of thermodynamics employ methodologies based on periodic density functional theory (DFT). ${ }^{18,119}$ A key benefit of DFT is its computational efficiency; it allows the ground-state energy of an intractable $3 N$-dimensional electron system to be expressed in terms of the much simpler three-dimensional electron density, $n(\boldsymbol{r})$ :

$$
E[n(\vec{r})]=T_{0}[n(\vec{r})]+\int V_{\mathrm{ion}}(\vec{r}) n(\vec{r}) \mathrm{d} \vec{r}+E_{\mathrm{h}}[n(\vec{r})]+E_{\mathrm{xc}}[n(\vec{r})]
$$

Here $E$ represents the electronic energy, $T_{0}$ is the kinetic energy of (non-interacting) electrons, $V_{\text {ion }}$ is the electrostatic potential due to atomic nuclei, $E_{\mathrm{h}}$ is the classical electronelectron (Hartree) interaction, and $E_{\mathrm{xc}}$ is the exchangecorrelation energy. By augmenting this expression with a term describing the electrostatic energy of the ion cores, it is thus possible to calculate the total energy of a collection of atoms (i.e., solids, liquids or gas phase molecules) at zero Kelvin. Finite-temperature thermodynamic quantities (enthalpies $\Delta H(T)$, entropies $\Delta S(T)$, and free energies $\Delta G(T)$ ) can also be calculated by evaluating the phonon spectrum of the relevant phases. ${ }^{120,121}$

The advantages of employing DFT calculations for hydrogen storage materials research are three-fold. First, the accuracy of computed thermodynamic quantities is generally quite good in comparison with experimental data, and in most cases agrees to within $\sim 15 \mathrm{~kJ} / \mathrm{mol} \mathrm{H}_{2} \cdot{ }^{105,113}$ While further improvement in accuracy is desirable - and, given the on-going development of new exchange correlation functionals, likely to continue-present techniques are more than sufficient to identify trends across different compounds and to identify materials having promising thermodynamics $(\Delta H=$ 20-50 kJ/mol $\mathrm{H}_{2}$ ) from those likely to be thermodynamic "dead ends" (having $\Delta H<0$ or $\Delta H>80 \mathrm{~kJ} / \mathrm{mol} \mathrm{H}_{2}$ ). Supporting this assertion, in a previous study we demonstrated a strong correlation between the calculated and experimental enthalpies of desorption for a variety of binary metal hydrides. ${ }^{105,113}$

A second strength of computation lies in its relative efficiency. Our experience has shown that the calculation of the room-temperature free energy change for a single reaction can be performed in a matter of days. ${ }^{37}$ On the other hand, experimental assessment of the same can take significantly longer. For example, in the case of a PCT measurement, a relatively large number of measurements at several temperatures and states of desorption are needed to assemble a van't Hoff plot (Fig. 4(d)). As mentioned above, this process is hindered by reactions having slow kinetics, in which case it may take several days to measure a single equilibrium PCT datapoint, and thus on the order of several weeks to months to extract $\Delta H$ and $\Delta S$.

In recognition of the efficiency with which computation can assess thermodynamic properties, several groups have employed a form of "computational screening" to rapidly search through a large number of reactions involving known compounds in order to identify hydride mixtures having favorable thermodynamics. ${ }^{37,99,113,122-126}$ This approach can vastly improve the useful throughput of experiments by narrowing the phase space of candidate materials to those exhibiting thermodynamic potential.

A final advantage of computation is its ability to make thermodynamic predictions of hypothetical new compounds or mixtures. Examples of this approach fall into two categories: first, several groups have used DFT to evaluate the binding energies of hydrogen to functionalized fullerenes or other compounds. ${ }^{127-131}$ While many promising compounds have been identified via this approach, realizing their synthesis has proven to be a challenge.

A second, and perhaps more promising example of the predictive power of computation relates to the construction of virtual phase diagrams. Given a mixture of reactants composed of $n$ elements, a complete description of the thermodynamics of hydrogen storage in this system would be provided by a $n-1$-dimensional phase diagram (where the $n$th dimension is assigned to gas phase $\mathrm{H}_{2}$ ). Although experiments can be used to evaluate these diagrams, their construction is a labor-intensive process. At present reliable phase diagrams for most complex or chemical hydrides are few in number, and diagrams for multi-component mixtures are virtually non-existent. Recently, ${ }^{132}$ a novel method has been introduced termed the grand canonical linear programming 
(GCLP) method. The GCLP method is capable of delineating all thermodynamically-realistic reactions occuring within a prescribed composition space. ${ }^{13,126,132}$ As initially constructed, the method relies upon DFT-calculated free energies, and focused on reactions within the $\mathrm{Li}-\mathrm{N}-\mathrm{Mg}-\mathrm{H}$ composition space. ${ }^{132}$ By predicting thermodynamicallyrealistic reaction pathways, this approach eliminates the need to "guess" at what reactions could occur. $99,113,133$

Despite the advantages afforded by first-principles computation, its utility for predicting the properties of new or hypothetical materials-i.e., compounds which have yet to be synthesized, or for which the crystal structure is not known - remains a key challenge. The source of these difficulties can be traced to the so-called "crystal structure problem," 134 that is, for a specified composition it is not (yet) possible to accurately predict the minimum energy crystal structure. Unfortunately, as an atomistic simulation technique, DFT calculations require knowledge of the composition and crystal structure of the compound in question. While it is possible to calculate an upper-bound to a phase's ground state energy by guessing at potential structures, this approach represents an uncontrolled approximation.

At present, the most reliable methods for crystal structure determination are synchrotron and neutron diffraction. ${ }^{135}$ However, two promising computational methods for the prediction of crystal structures have recently emerged. The first of these approaches, the so-called prototype electrostatic ground state (PEGS) approach, ${ }^{136}$ has been shown to be of great value in predicting ground state structures for compounds (such as borohydrides) in which ionic interactions constitute a significant fraction of the bonding. For example, the PEGS approach recently predicted a new crystal structure for $\mathrm{Mg}\left(\mathrm{BH}_{4}\right)_{2}$ which was lower in energy than any other known structure. ${ }^{137}$ A second technique, the USPEX method, ${ }^{138}$ is a general technique based on a biologicallyinspired evolutionary algorithm. Although it has been mostly used to study high-pressure geologic phases, USPEX could be applicable to a wide variety of compounds including hydrides. As these and other methods (i.e., database searching and structure enumeration/cluster expansion ${ }^{113}$ ) of crystal structure prediction evolve, so too will predictive applications of DFT.

An additional challenge for the application of DFT in hydrogen storage materials research arises for systems exhibiting van der Waals interactions. Materials within this category include molecular crystals (such as $\mathrm{NH}_{3} \mathrm{BH}_{3}$ ) and systems involving physisorptive $\mathrm{H}_{2}$ adsorption (such as on MOFs). As DFT does not account for dispersion interactions, one should consider application of alternative techniques (such as quantum chemical cluster methods or quantum Monte Carlo) for systems in this category. Additional information regarding DFT, including its underpinnings and broader application to hydrogen storage materials research, can be found elsewhere. ${ }^{113}$

In closing our discussion of thermodynamics it is important to recognize that favorable thermodynamics represents a necessary but not sufficient condition for solving the hydrogen storage problem. The rate at which the storage reaction proceeds is also a key consideration. This latter attribute, also referred to as kinetics, is discussed in detail in the following section.

\section{Kinetics}

Kinetics focuses on measuring and understanding the rate and pathway involved in hydrogen uptake and release processes. Sufficient fuel system kinetics are required in order to both supply an adequate flow of hydrogen to power the vehicle as well as enable fast refueling. The goal of kinetics research is to understand the dynamic properties, such as surface interactions, hydrogen-host storage mechanisms, and mass transport phenomena, which are intrinsic to a sample [which includes sample processing and/or catalytic additions (e.g. scaffolds, catalysts)]. Ideally one would like to identify the largest activation energy barrier(s) which controls the rate of a hydrogen uptake or release reaction. However, the task of identifying rate-limiting step(s) is usually non-trivial, especially in multicomponent reactions involving complex hydrides. In the following section we introduce the types of kinetic barriers associated with each material class, and discuss methods aimed at overcoming these barriers.

\section{Kinetic barriers as applied to each materials class}

Conventional metal hydrides. In conventional metal hydrides absorption takes place via surface dissociation of hydrogen molecules followed by diffusion of hydrogen atoms into the metal. Rate-limiting steps could therefore include: surface dissociation of $\mathrm{H}_{2}$, diffusion of hydrogen atoms in the metal, and nucleation and growth of the hydride phase. The opposite processes occur during hydrogen desorption, namely hydrogen atom diffusion through the hydride, recombination of molecular hydrogen at the hydride surface, and nucleation and growth of the metal phase.

Since the surface of the metal particle plays a key role in both uptake and release, activation of the material may be necessary. This is a process whereby nascent particle surface is generated (e.g., via breaking up the passivating oxide layer in $\mathrm{Mg}$-based hydrides) in order to facilitate the hydrogen dissociation reaction. Incorporating elements which act as a hydrogen dissociation catalyst or increasing surface area by decreasing crystal grain size are two methods used to increase kinetic response in these materials.

Complex and chemical hydrides. Research in complex and chemical hydrides has largely focused on identifying new materials and reactions which possess favorable hydrogen capacities and hydrogen reaction thermodynamics. As a result, the issue of kinetics remains perhaps the primary challenge associated with this materials class. Hydrogen reactions in complex hydrides are generally more complicated than in conventional metal hydrides since both hydrogen and other constituent elements are involved at various steps. For example, desorption from complex hydrides typically involves the bond-breaking of anionic complexes (e.g., $\mathrm{BH}_{4}{ }^{-}$) and recombination into $\mathrm{H}_{2}$. In turn, the constituent metal elements may have to undergo long-range transport to nucleate new phases in the decomposition sequence. Upon hydrogenation, the processes reverse, sometimes with altered reaction pathways. 
Catalysts or additives are commonly used in complex and chemical hydrides to accelerate the rates of storage reactions. The most famous example in a complex hydride involves the addition of a Ti-containing catalyst to $\mathrm{NaAlH}_{4}$ mentioned above. $^{32}$ However, the detailed atomistic mechanism responsible for the kinetic enhancement in this material remains elusive, despite a large number of studies over the last decade (a detailed summary of the numerous mechanisms proposed for this effect is beyond the scope of this review). Most significantly, none of the proposals have allowed for the prediction of new, optimized catalysts.

As in conventional metal hydrides, reducing particle (crystal) size remains an essential step in improving hydrogen reaction kinetics of complex hydrides. A related idea which shows promise involves the use of high surface area scaffolding to confine very small particles of reactant hydride materials. This approach has proven effective in improving hydrogen reaction kinetics, lowering hydrogen desorption temperatures, and eliminating unwanted species. ${ }^{76}$

Most complex and chemical hydride reactions involve the formation of new solid-state product phases upon dehydriding. Hence, these new phases must be nucleated, a process which could serve as a rate-limiting step for $\mathrm{H}_{2}$ release. One technique which can be used to eliminate or lower the barrier to nucleation is to "seed" the reactants with a small amount of the relevant product phases. This idea, also known as "product seeding," has been employed to accelerate kinetics in chemical hydrides such as $\mathrm{NH}_{3} \mathrm{BH}_{3},{ }^{92}$ as well as in complex hydride reactions involving amide-containing mixtures, $\mathrm{LiNH}_{2}+\mathrm{MgH}_{2}{ }^{139}$

This idea of product seeding has also been extended to a mechanism of "self-catalyzed" reactions, ${ }^{97}$ whereby a mixture of reactants (or so-called Reactive Hydride Composite ${ }^{140}$ ) produces a low-temperature hydrogen decomposition that produces products which serve to "seed" higher temperature decomposition reactions. Specifically, in the mixture $2 \mathrm{LiNH}_{2}+\mathrm{LiBH}_{4}+\mathrm{MgH}_{2}$, an ancillary reaction between molten $\mathrm{Li}_{4} \mathrm{BN}_{3} \mathrm{H}_{10}$ and $\mathrm{MgH}_{2}$ generates $\mathrm{Li}_{2} \mathrm{Mg}(\mathrm{NH})_{2}$ at about $100{ }^{\circ} \mathrm{C}$, which subsequently acts as nuclei for a higher temperature reversible reaction. This work demonstrated in situ product seeding as an effective scheme for improving complex hydride reaction kinetics; it remains to be seen if it can be exploited in other hydrogen storage materials.

Sorbent materials. Hydrogen storage on high surface area materials generally exhibits excellent kinetic properties, as the physisorption and desorption of $\mathrm{H}_{2}$ molecules and the transport of gaseous $\mathrm{H}_{2}$ through the material tend to be fast processes.

A relatively new approach to storing hydrogen in sorbents is based on the "spillover" mechanism, ${ }^{63}$ which utilizes a hydrogen dissociation catalyst to generate atomic hydrogen. A key advantage of spillover is its ability to operate at room temperature rather than at $77 \mathrm{~K}$ (which is the typical temperature requirement for uptake in sorbents without spillover). The higher operating temperatures reflect the possibility of stronger bonding between atomic hydrogen and the host sorbent compared to the weak physisorptive interactions involving molecular $\mathrm{H}_{2}$. Although the initial results from this approach are intriguing, early analyses of the kinetics of spillover suggest that the hydrogen uptake reaction can be slow. As the precise mechanism by which spillover occurs is still a topic of intense research, it is not yet possible to definitively identify the rate-limiting processes.

\section{Techniques for kinetic assessment}

Laboratory methods for determining the kinetic properties of hydrogen storage reactions are typically the same as those previously discussed for assessing capacity-namely, volumetric or gravimetric methods. However, from a practical standpoint, volumetric methods are typically the methods of choice, as gravimetric methods suffer from inaccuracies in the measurement of sample temperature (arising from poor heat transfer at low gas pressures). Complimentary methods, such as temperature programmed mass spectrometry (TPD-MS), X-ray (XRD) and neutron diffraction, and infrared (IR), Raman, and nuclear magnetic resonance (NMR) spectroscopies are usually also required to elucidate the underlying hydrogen (de)sorption process.

The "optimal" experimental setup for evaluating the kinetic properties of a hydrogen storage reaction depends on whether one's focus is directed towards system properties or materials properties. System-level kinetic assessments could range from an examination of heat transfer during an exothermic refuelling reaction to scanning hydrogen release performance over various sections of a storage test bed. On the other hand, studies of materials-level kinetics usually focus on understanding and optimizing fundamental kinetic properties. An example experimental kinetic protocol for a given storage material might involve testing a set of constant temperature ramp rates (monitoring $\mathrm{H}_{2}$ concentration versus time), simultaneously ensuring that all other experimental parameters (e.g. sample size, pressure, sample packing density, void volume, etc.) remain constant. Using data such as this, kinetic models can be constructed to identify rate-controlling reaction steps and activation energies $\left(E_{\mathrm{a}}\right)$. More fundamental kinetics studies, which probe surface interactions, mass (hydrogen or host elements) and energy transfer, and binding processes, often require specially-designed sample cells and instruments in order to accurately examine the desired kinetic effect in isolation. Regardless of the perspective, the proper design of all kinetic measurements requires consideration of several factors, including: gas impurities, leaks, pressure effects (e.g. reservoir selection), sample size-to-volume ratio, heat transfer efficiency, and thermal effects. Detailed discussion of these considerations are covered in ref. 81.

Computational techniques can be used to ascertain the activation barriers associated with various processes, and to search for rate-limiting steps. Molecular dynamics (MD) simulations are a powerful tool for modeling the evolution of a system under various thermodynamic conditions (e.g., fixed temperature, fixed pressure, etc.). MD simulations based on quantum-mechanical energetics (e.g., ab initio MD) can be used to study the chemistry of bond-breaking and formation in these systems, including possible rate limiting steps such as hydrogen dissociation and recombination at material surfaces. These simulations tend to be significantly 
limited in the time-scales which they can access, but efficient techniques to extend the timescale of these simulations are an active area of research. ${ }^{141}$ Another important tool for modeling kinetic processes are transition-state finders, such as the nudged elastic band method ${ }^{142}$ and others. ${ }^{141}$ These methods may be coupled with first-principles DFT methods to elucidate the energetic and geometric pathway associated with various chemical reactions or diffusive events. These types of techniques have already been used in studying the kinetics of various hydride materials, most notably $\mathrm{NaAlH}_{4}{ }^{143,144}$

\section{Other key attributes}

In this section, we briefly highlight three additional attributes which are essential considerations for materials-based hydrogen storage research and development: purity, cycle life, and efficiency.

\section{Purity}

Purity can be considered from two perspectives: (a) purity of the incoming hydrogen delivered to the material storage system, and (b) purity of the effluent hydrogen to the fuel cell power plant. In the former type, impurities such as water, oxygen, or particulates are exposed to the storage material from the hydrogen source at the refueling station. Additionally, contamination could occur inadvertently during initial loading of the storage material. Depending on the reactivity of the material, the consequences of exposure to a contaminant can range from preferential adsorption of a non-hydrogen gas and subsequent loss of $\mathrm{H}_{2}$ capacity, to an irreversible reaction (e.g. between $\mathrm{AlH}_{3}$ and oxygen to form $\left.\mathrm{Al}(\mathrm{OH})_{3}\right)$. In either case, a portion of the material has been rendered permanently or temporarily inactive to bind hydrogen, leading to a reduction in capacity and/or kinetics. If the material is repeatedly exposed to impurities over subsequent refueling cycles, the effect to capacity and performance can be cumulative, as demonstrated in conventional metal hydrides. ${ }^{145,146}$ In some cases (e.g. sorbent systems), impurities can be removed by exposure to high vacuum and/or heating. However for complex and chemical hydrides contamination from even trace amounts of impurities, particularly oxygen or moisture, is unable to be reversed on-board. Only recently have researchers begun to examine and quantify the effects of hydrogen storage material contamination in an automotive environment (e.g. using scenarios based on NFPA, ISO and SAE). ${ }^{147}$ These studies will be helpful in establishing mitigation methods for safety codes and standards, identifying trade-offs between contamination level and performance, and understanding differences in reactivity for various material-impurity combinations.

The second category of $\mathrm{H}_{2}$ purity refers to the effluent hydrogen released from the hydrogen storage material and delivered to the fuel cell. Given the high chemical sensitivity of the fuel cell and desire to minimize fuel dilution, hydrogen quality guidelines for fuel cell vehicles have been established (SAE-2719). Specifically, the hydrogen supplied to the fuel cell should support a fuel index of $\geq 99.99 \%$ and should limit the following concentrations of non-hydrogen species: 5 ppm water, 1 ppm carbon dioxide and $0.1 \mathrm{ppm}$ ammonia (see ref. 149 for full listing impurity tolerances). While some impurities such as nitrogen gas only lead to a dilution of the fuel, others such as ammonia induce an irreversible poisoning of the fuel cell catalyst and membrane, causing a marked degradation in fuel cell performance. Hydrogen ICEs, however, may possess higher tolerances to such impurities.

The hydrogen release process for sorbent materials and conventional metal hydrides does not typically involve the release of non-hydrogen byproducts (assuming none were initially introduced to the material). On the contrary, for complex and chemical hydrides potential fuel cell poisons such as ammonia $\left(\mathrm{NH}_{3}\right)$ or diborane $\left(\mathrm{B}_{2} \mathrm{H}_{6}\right)$ are often released prior to or simultaneously with hydrogen. The liberation of these contaminants can be assessed using temperatureprogrammed-desorption mass spectrometry (TPD-MS) or residual gas analysis (RGA), which enables the concentrations of various volatile species (e.g. $\mathrm{H}_{2}, \mathrm{NH}_{3}, \mathrm{H}_{2} \mathrm{O}, \mathrm{O}_{2}$, etc. $)$ to be monitored in the effluent gas stream. More rigorous methods such as Draeger Tube tests (for $\mathrm{NH}_{3}$ detection) are often used for sensitive quantification of trace gases. ${ }^{150}$

\section{Cycle life}

Cycle life requirements are based on the expectation that the fuel system will last the entire life of the vehicle (up to $241402 \mathrm{~km}$ or 150000 miles). More specifically, the initial performance metrics of the storage material should be preserved over 1500 hydrogen discharge-charge cycles (DOE 2015 target). Given that chemical hydride storage materials are intended as single-use fuels and will be regenerated off-board, cycle life testing does not apply to the material itself. Storage systems based on on-board reversible materials, however, must possess chemical and structural stability with respect to cycling in environments which include thermal variations (e.g. -40 to $85{ }^{\circ} \mathrm{C}$ ) and mechanical shock (e.g. vibrations, rattling). In regards to structural stability, the storage system should be engineered to mitigate pulverization of the storage material powders or tablets, for example by incorporating a grid-like support structure. In regards to chemical stability, as mentioned above some classes of storage materials, particularly chemical and complex hydrides, exhibit undesirable side reactions which liberate non-hydrogen byproducts. Therefore elements which participate in the hydrogen storage reaction (e.g. nitrogen in $\mathrm{NH}_{3}$ ) are continuously lost over many discharge-charge cycles, translating to a reduction in hydrogen capacity. Although it is usually unnecessary to invest in long-term cycling studies at the earlier stages of materials development, at a minimum it is important to evaluate a given material at a fraction of the ultimate cycling target to identify any obvious degradation in capacity or kinetics. Such preliminary cycling studies can provide information to guide materials down-selections.

\section{Efficiency}

One of the principal drivers for displacing current vehicles based on gasoline ICEs with those utilizing hydrogen fuel cells is the prospect of achieving improved energy efficiency. A vital part of realizing such vehicle-level efficiency gains lies with the creation of an efficient hydrogen storage system. Analyses of 
materials-based storage efficiency involves tracking energy consumption over the hydrogen release and uptake (or regeneration) process. Depending on the design of the storage system such analyses can be complex, and lacking a detailed prototype, may necessitate numerous assumptions (e.g. estimating energy losses due to heat transfer). Energy efficiencies are typically reported as a percentage of the lower heating value (LHV) of hydrogen $(120 \mathrm{MJ} / \mathrm{kg} \mathrm{H}$ ) which represents the upper bound of available energy.

As a baseline for materials-based hydrogen storage, current $70 \mathrm{MPa}$ compressed systems require work (energy) for compression which varies between approximately $8.5 \%$ and $15 \% \mathrm{H}_{2} \mathrm{LHV}$ depending on the assumptions (e.g. compressor type, degree of intercooling, etc.). ${ }^{151-153}$ Conversely, liquid hydrogen storage requires a significantly greater energy input, $\sim 30 \% \mathrm{H}_{2}$ LHV in practice, depending on the capacity of the liquefaction plant. $^{152}$ All materials-based storage systems involve both hydrogen discharging and charging (or regeneration) steps whose energy losses must be accounted for. The general trend is the lower the reaction enthalpy $(\Delta H)$, the greater the storage system efficiency. This relationship stems from the harsher hydrogen release conditions (e.g. higher temperatures) and the larger demands for managing ejected heat during charging that come with high enthalpy reactions. The relationship between heat rejection (translating to required cooling load), reaction enthalpy $(\Delta H)$, and refueling time is plotted in Fig. 5. ${ }^{148}$ This data suggests that, from a refueling efficiency perspective, it is highly desirable to target materials with enthalpies in the range of $20-30 \mathrm{~kJ} / \mathrm{mol} \mathrm{H}_{2}$.

Storage systems based on conventional metal hydrides (e.g. $\mathrm{AB}_{5}, \mathrm{AB}_{2}$ and $\mathrm{BCC}$ alloys) can have favorable efficiencies. Stemming from their characteristically low reaction enthalpies $\left(20-40 \mathrm{~kJ} / \mathrm{mol} \mathrm{H}_{2}\right)$, conventional metal hydrides are capable of releasing hydrogen at ambient temperature and require modest pressures (e.g. $<10 \mathrm{MPa})$ for hydrogen absorption. Assuming the heat ejected during refueling can be dissipated with no energy consumption (e.g., $170 \mathrm{~kW}$ cooling load required for a $5 \mathrm{~min}$ refuel; see Fig. 5), and that the FC waste heat can provide the needed

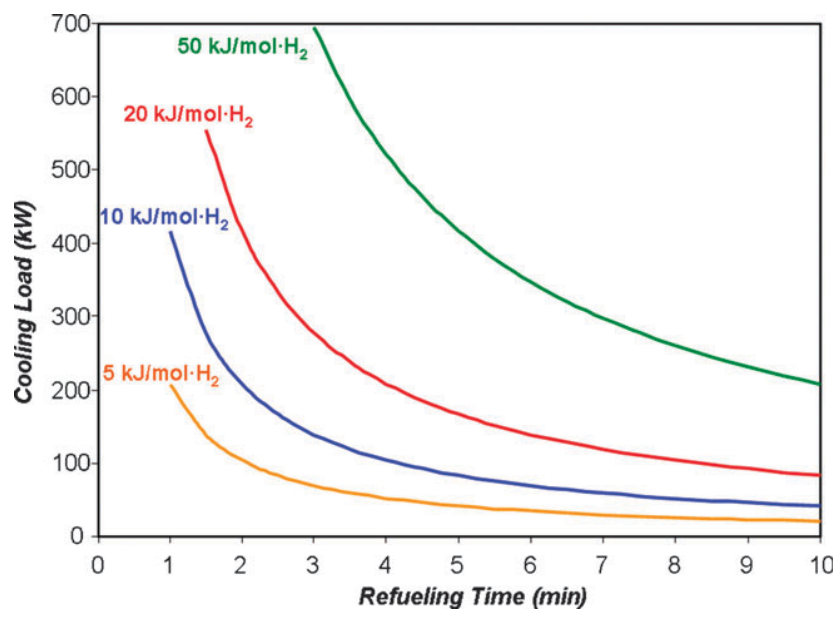

Fig. 5 Theoretically required cooling load $(\mathrm{kW})$ as a function of refuelling time (min) for absorbing $5 \mathrm{~kg}$ of $\mathrm{H}_{2}$ into storage materials of various $\Delta H .^{148}$ heat of desorption, a $20 \mathrm{~kJ} / \mathrm{mol} \mathrm{H}_{2}$ material would be $95-96 \%$ efficient with respect to hydrogen uptake and release. This efficiency value reflects the $4-5 \%$ LHV required for 20 bar compression. ${ }^{152}$

Complex hydrides often require high temperatures (pressures) for hydrogen release (absorption), stemming from high reaction enthalpies and/or poor kinetic attributes. The additional heat necessary to achieve temperatures beyond that available from fuel cell coolant heat $\left(\sim 80{ }^{\circ} \mathrm{C}\right)$ could be accomplished by burning fuel. However, the energy which is used to liberate fuel penalizes the storage efficiency and therefore should be avoided. In addition, and as mentioned above, it may be a challenge to manage the large amount of heat produced during refill of a complex hydride with a large enthalpy. As an example, a hydrogen storage reaction possessing a $\Delta H$ of $50 \mathrm{~kJ} / \mathrm{mol} \mathrm{H} \mathrm{H}_{2}$ translates to a $420 \mathrm{~kW}$ cooling requirement for a $5 \mathrm{~min}$ refueling time.

Storage systems based on chemical hydrides should account for inefficiencies associated with both releasing hydrogen and regenerating the hydride off-board (the current DOE target for efficiency of the storage system is $60 \%$ ). As an example, the hydrolysis of sodium borohydride $\left(\mathrm{NaBH}_{4}\right)$ has been extensively explored as a potential hydrogen storage option and has even been implemented on-board a demonstration vehicle. $^{154}$ The exothermic hydrolysis reaction between $\mathrm{NaBH}_{4}$ and $\mathrm{H}_{2} \mathrm{O}$ produces sodium borate $\left(\mathrm{NaBO}_{2}\right)$, hydrogen, and $55 \mathrm{~kJ}$ of heat per mole $\mathrm{H}_{2} .{ }^{155}$ Based on ref. 151, which assumes a PEM fuel-cell efficiency of $50 \%$, the heat generation from the sodium borohydride storage system would introduce an $46 \%$ increase above the heat rejection from the fuel cell alone. Given that heat management of PEM fuel cells already presents engineering challenges, this additional thermal load would likely exacerbate heat transfer management. Other chemical hydride storage reactions such as the thermolysis of ammonia borane that are virtually thermal-neutral, should present far less heat management issues. Perhaps more daunting are the projected energy requirements for $\mathrm{NaBH}_{4}$ regeneration, which range from $54 \%$ to $69 \% \mathrm{H}_{2} \mathrm{LHV}^{73}$-far above the $40 \%$ $\mathrm{H}_{2}$ LHV limit (2015 DOE target). Additionally, a great deal of progress is currently being made in identifying energy-efficient means for the regeneration of ammonia borane. ${ }^{67,71,74,92}$

\section{Conclusions}

One of the key enablers for the commercialization of hydrogen fuel cell vehicles is the identification of efficient and cost-effective means for on-board storage of hydrogen. While current approaches to storage rely on compression or (energy-intensive) liquefaction of hydrogen, these techniques do not have the potential to meet all of the targeted attributes necessary for widespread FCV adoption. Consequently, materials-based hydrogen storage has been identified as perhaps the only approach towards achieving performance and cost targets.

In this review we have focused on how three of the critical attributes necessary for a viable hydrogen storage systemcapacity, thermodynamics and kinetics-motivate the development of new hydrogen storage materials. The four key classes of candidate materials, conventional metal 
hydrides, complex hydrides, sorbents and chemical hydrides, were introduced and their respective prospects for future progress were discussed. A summary of the advantages and disadvantages of each materials class is given below:

- Conventional metal hydrides possess high volumetric capacities, favorable kinetics, efficiencies and thermodynamics, and are reversible on-board the vehicle. However, the gravimetric capacities for this class are in practice rather low $(\sim 2 \mathrm{wt} \%)$, with no clear pathway for improvement after several decades of study.

- Complex hydrides typically have both high gravimetric and volumetric capacities and the potential to be on-board reversible thanks to the identification of a number of materials with favorable thermodynamics. The primary challenge associated with this class of materials is poor hydrogen uptake/release kinetics.

- Sorbents have been shown to exhibit high gravimetric capacities and are on-board reversible with facile kinetics. Modest volumetric capacities and poor thermodynamics (requiring cryogenic temperatures) currently remain the key drawbacks.

- Chemical hydrides possess high hydrogen capacities by both volume and weight. The two critical barriers typically associated with this class are irreversibility and energy inefficiency. While some chemical hydride materials (reactions) have reasonable kinetics and are thermoneutral or even endothermic, others can be excessively exothermic and require significant heat management.

Having identified the major challenges facing each materials class, it is imperative that research priorities be aligned towards addressing these challenges. For example, for complex hydrides, theorists have begun to examine fundamental aspects of kinetics toward identifying rate-limiting reaction steps for the subsequent rational design of catalysts. Likewise, for sorbents, today's research objectives are typically directed at increasing hydrogen-host binding toward nearambient temperature storage via creation of open metal sites in MOFs or investigation of the potential for spillover. For chemical hydrides, future directions should be focused on identifying energy-efficient and cost-effective off-board regeneration pathways.

It is clear that a great deal of progress has been achieved over the last decade in the area of materials-based hydrogen storage. Materials from the past have been resuscitated with the help of novel processing schemes and strategies for destabilization. New materials are continuously being discovered. However, despite these gains, no known material exhibits all of the attributes required for a viable storage system. Discovering this material remains a tremendous challenge and provides exciting opportunities for the materials research community.

\section{Acknowledgements}

D. J. S., A. S. and J. Y. acknowledge financial support from the U.S. Department of Energy's Hydrogen Storage Engineering Center of Excellence, contract no. DE-FC36-GO19002. C. W. acknowledges financial support from the U.S. Department of Energy under grant DE-FG02-07ER46433 and from the National Science Foundation under grant CBET-0730929. J. Y. acknowledges the helpful discussions with Shinichi Hirano.

\section{References}

1 Mobility 2030: Meeting the Challenges to Sustainability, World Business Council for Sustainable Development, (2004). ISBN: 2-940240-57-4, Geneva, Switzerland. Available on-line at: http:// www.wbcsd.org/web/publications/mobility/mobility-full.pdf.

2 Annual Energy Review 2006, Energy Information Administration, U.S. Department of Energy (June 2007). http://www.eia.doe.gov/aer.

3 T. J. Wallington, J. L. Sullivan and M. D. Hurley, Meteorol. Z., 2008, 17, 109 .

4 Energy and Transportation: Challenges for the Chemical Sciences in the 21st Century, Organizing Committee for the Workshop on Energy and Transportation, The National Academies Press, Washington, D.C., 2003.

5 The Hydrogen Economy: Opportunities, Costs, Barriers and R\&D Needs, Committee on Alternatives and Strategies for Future Hydrogen Production and Use, The National Academies Press, Washington, D.C., 2004.

6 B. C. H. Steele and A. Heinzel, Nature, 2001, 414, 345.

7 Based on their lower heating values, $1 \mathrm{~kg} \mathrm{H}_{2}=120.21 \mathrm{MJ}$; $1 \mathrm{~L}$ low-sulfur gasoline $=31.67 \mathrm{MJ}$.

8 U.S. Department of Energy Hydrogen Program 2006 Annual Merit Review Proceedings, Technology Validation, http://www. hydrogen.energy.gov/pdfs/review06/tv_9_frenette\%20.pdf and http://www.fueleconomy.gov/.

9 L. Schlapbach and A. Züttel, Nature, 2001, 414, 353.

$1010.6 \mathrm{~km} / \mathrm{L}$ is approximately equal to the 2004 U.S. average vehicle fleet fuel economy. U.S. Department of Transportation, National Highway Traffic Safety Administration, Automotive Fuel Economy Program Annual Update Calendar Year 2004, DOE HS 809512. http://www.nhtsa.dot.gov/staticfiles/DOT/NHTSA/Vehicle $\%$ 20Safety/CAFE/2004_Fuel Economy_Program.pdf.

11 The analysis conducted by the U.S. National Research Council in ref. 8 adopted fuel economy improvement ratios of 2.4 and 1.66 for a FCV relative to an advanced ICE or HEV, respectively.

12 S. Lasher, presented in part of the U.S. Department of Energy Hydrogen Program 2008 Annual Merit Review, Analyses of Hydrogen Storage Materials and On-Board Systems, Arlington, VA, June, 2008. http://www.hydrogen.energy.gov/pdfs/review08/ st 1 lasher.pdf.

13 Note that the volumetric energy density of $70 \mathrm{MPa}$ hydrogen, $1.3 \mathrm{kWh} / \mathrm{L}$, which is the density of the gas alone, is unable to satisfy the 2015 DOE system-level targets due to the additional volume required for system components such as the containment vessel.

14 Hydrogen Delivery, Liquefaction and Compression, Praxair presentation at Strategic Initiatives for Hydrogen Delivery Workshop-May 7, 2003. http://www1.eere.energy.gov/hydrogen andfuelcells/pdfs/liquefaction_comp_pres_praxair.pdf.

15 S. Satyapal, presented in part of the U.S. Department of Energy Hydrogen Program 2008 Annual Merit Review, Hydrogen Storage Sub-Program Overview, Arlington, VA, June, 2008. http://www.hydrogen.energy.gov/pdfs/review08/st_0_satyapal.pdf.

$16 \mathrm{http}: /$ wwwl.eere.energy.gov/hydrogenandfuelcells/storage/pdfs/ targets_onboard_hydro_storage.pdf.

17 S. Satyapal, J. Petrovic, C. Read, G. Thomas and G. Ordaz, Catal. Today, 2007, 120, 246.

$18 \mathrm{http} / / /$ wwwl.eere.energy.gov/hydrogenandfuelcells/tech_validation/ fleet_demonstration.html.

19 A $805 \mathrm{~km}$ range was selected using data for the volume of 2007 U.S. vehicle sales $v s$. driving range. The approximate median driving range as determined by the. U.S. EPA drive cycle is $500 \mathrm{mi}$. See ref. 16 for more information.

20 For comparison, an average U.S. automobile fuel system of today has a capacity of 19.8 gallons and a mass (including gasoline) of approximately $74 \mathrm{~kg}$, yielding a specific energy of $8.9 \mathrm{kWh} / \mathrm{kg} .{ }^{17}$ Dividing the energy content of the gasoline by the volume of the system $(107 \mathrm{~L})$ yields an energy density of $6.2 \mathrm{kWh} / \mathrm{L}$.

21 A. C. Switendick, Z. Phys. Chem. N. F., 1979, 117, 89. 
22 Based on the crystal structure of $\mathrm{VH}_{2}$ and assuming a materials density equal to the single-crystal density; see Table 2, reaction 2.

23 D. H. Everett, Pure Appl. Chem., 1972, 31, 577.

24 Phase Diagrams of Binary Hydrogen Alloys, ed. F. D. Manchester, ASM, Materials Park, OH, 2000.

25 Hydrogen in Intermetallic Compounds II, in Topics in Applied Physics, ed. L. Schlapbach, Springer, Berlin, 1992, vol. 72, pp. 15-258.

26 M. Dornheim, S. Doppiu, G. Barkhordarian, U. Boesanberg, T. Klassen, O. Gutfleisch and R. Bormann, Scr. Mater., 2007, 56, 841.

27 G. Sandrock, J. Alloys Compd., 1999, 293-295, 877.

28 B. Sakintuna, F. Lamari-Darkrim and M. Hirscher, Int. J. Hydrogen Energy, 2007, 32, 1121.

29 A. Züttel, S. Rentsch, P. Fisher, P. Wenger, P. Sudan, $\mathrm{Ph}$. Mauron and Ch. Emmenegger, J. Alloys Compd., 2003, 356, 515.

30 A. Züttel, P. Wenger, S. Rentsch and P. Sudan, J. Power Sources, 2003, 118, 1

31 Y. Nakamori, H. Li, K. Miwa, S. Towata and S. Orimo, Mater. Trans., 2006, 47, 1898.

32 B. Bogdanović and M. Schwickardi, J. Alloys Compd., 1997, 253-254, 1

33 P. Chen, Z. T. Xiong, J. Z. Luo, J. Y. Lin and K. L. Tan, Nature, 2002, 420, 302.

34 H. J. Schlesinger and H. C. Brown, J. Am. Chem. Soc., 1940, 62, 3429.

35 J. J. Vajo and S. L. Skeith, J. Phys. Chem. B, 2005, 109, 3719.

36 J. J. Reilly and R. H. Wiswall, Inorg. Chem., 1968, 7, 2254.

37 D. J. Siegel, C. Wolverton and V. Ozoliņš, Phys. Rev. B: Condens. Matter Mater. Phys., 2007, 76, 134102.

38 J. Yang, A. Sudik and C. Wolverton, J. Phys. Chem. C, 2007, 111, 19134.

39 D. Sun, S. Srinivasan, T. Kiyobayashi, N. Kuriyama and C. M. Jensen, J. Phys. Chem. B, 2003, 107, 10176.

40 F. E. Pinkerton, M. S. Meyer, G. P. Meisner and M. P. Balogh, J. Alloys Compd., 2007, 433, 282.

41 F. E. Pinkerton, M. M. Meisner, M. Balogh and M. Kundrat, J. Phys. Chem. B, 2005, 109, 6.

42 M. Aoki, K. Miwa, T. Noritake, G. Kitahara, Y. Nakamori, S. Orimo and S. Towata, Appl. Phys. A: Mater. Sci. Process., 2005, 80, 1409.

43 W. Luo, J. Alloys Compd., 2004, 381, 284; Z. Xiong, G. Wu, J. Hu and P. Chen, Adv. Mater., 2004, 16, 1522.

44 S. Orimo, Y. Nakamori, J. R. Eliseo, A. Züttel and C. M. Jensen, Chem. Rev., 2007, 107, 4111.

45 W. Grochala and P. P. Edwards, Chem. Rev., 2004, 104, 1283.

46 E. Poirier, R. Chahine, P. Bénard, G. Dorval-Douville, L. Lafi and P. A. Chandonia, Langmuir, 2006, 22, 8784.

47 R. G. Ding, J. J. Finnerty, Z. H. Zhu, Z. F. Yan and G. Q. Lu, Encyclopedia of Nanoscience and Nanotechnology, Am. Science Publishers, 2004, vol. X, pp. 1-21.

48 R. Ströbel, J. Garche, P. T. Moseley, L. Jörissen and G. Wolf, J. Power Sources, 2006, 159, 781.

49 Y. Zhao, Y.-H. Kim, A. C. Dillon, M. J. Heben and S. B. Zhang, Phys. Rev. Lett., 2005, 94, 155504.

50 A. C. Dillon and M. J. Heben, Appl. Phys. A: Mater. Sci. Process., 2001, 72, 133.

51 R. Chahine and T. K. Bose, Int. J. Hydrogen Energy, 1994, 19, 161.

52 H. Li, M. Eddaoudi, M. O'Keeffe and O. M. Yaghi, Nature, 1999, 402, 276.

53 M. Eddaoudi, D. B. Moler, H. Li, B. Chen, T. M. Reineke, M. O'Keeffe and O. M. Yaghi, Acc. Chem. Res., 2001, 34, 319.

54 H. Furukawa, M. A. Miller and O. M. Yaghi, J. Mater. Chem., 2007, 17, 3197.

55 D. J. Collins and H. C. Zhao, J. Mater. Chem., 2007, 17, 3154.

56 U. Mueller, M. Schubert, F. Teich, H. Puetter, K. Schierle-Arnt and J. Pastré, J. Mater. Chem., 2006, 16, 626.

57 H. Frost and R. Q. Snurr, J. Phys. Chem. C, 2007, 111, 18794.

58 K. S. Park, Z. Ni, A. P. Côté, J. Y. Choi, R. Huang, F. J. UribeRomo, H. K. Chae, M. O'Keeffe and O. M. Yaghi, Proc. Natl. Acad. Sci. U. S. A., 2006, 103, 10186.

59 A. P. Côté, A. I. Bennin, N. W. Ockwig, M. O'Keeffe, A. Matzger and O. M. Yaghi, Science, 2005, 310, 1166.
60 T. C. M. Chung, Y. Jeong, Q. Chen, A. Kleinhammes and Y. Wu, J. Am. Chem. Soc., 2008, 130, 6668.

61 X.-S. Wang, S. Ma, P. M. Forster, D. Yuan, J. Eckert, J. J. López, B. J. Murphy, J. B. Parise and H.-C. Zhou, Angew. Chem., Int. Ed., 2008, 47, 7263.

62 L. J. Murray, M. Dincă and J. R. Long, Chem. Soc. Rev., 2009, 38, 1294.

63 Y. Li and R. T. Yang, J. Am. Chem. Soc., 2006, 128, 8136.

64 J. L. C. Rowsell and O. M. Yaghi, Angew. Chem., Int. Ed., 2005, 44, 4670.

65 D. Zhao, D. Q. Yuan and H.-C. Zhou, Energy Environ. Sci., 2008, $1,222$.

66 L. F. Wang and R. T. Yang, Energy Environ. Sci., 2008, 1, 268.

67 F. H. Stephens, V. Pons and R. T. Baker, Dalton Trans., 2007, 2613.

68 S. C. Amendola, M. Binder, S. L. Sharp-Goldman, M. T. Kelly and P. J. Petillo, US Pat., 6,534,033 B1, 2003.

69 Q. Zhang, G. M. Smith and Y. Wu, Int. J. Hydrogen Energy, 2007, 32, 4731

70 G. P. Pez, A. R. Scott, A. C. Cooper and H. S. Cheng, US Pat., 7,429,372 B2, 2004

71 R. P. Shrestha, H. V. K. Diyabalanage, T. A. Semelsberger, K. C. Ott and A. K. Burrell, Int. J. Hydrogen Energy, 2009, 34, 2616.

72 C. W. Yoon, P. J. Carroll and L. G. Sneddon, J. Am. Chem. Soc., 2009, 131, 855.

73 Independent Review Panel, Go/No-Go Recommendation for Hydrolysis of Sodium Borohydride for On-Board Vehicular Hydrogen Storage, NREL/MP-150-42220, Golden, CO, 2007.

74 C. W. Hamilton, R. T. Baker, A. Staubitz and I. Manners, Chem. Soc. Rev., 2009, 38, 279.

75 T. B. Marder, Angew. Chem., Int. Ed., 2007, 46, 8116.

76 A. Gutowska, L. Li, Y. Shin, C. M. Wang, X. S. Li, J. C. Linehan, R. S. Smith, B. D. Kay, B. Schmid, W. Shaw, M. Gutowski and T. Autrey, Angew. Chem., Int. Ed., 2005, 44, 3578.

77 S. Zhang, A. F. Gross, S. L. Van Atta, M. Lopez, P. Liu, C. C. Ahn, J. J. Vajo and C. M. Jensen, Nanotechnology, 2009, 20, 204027.

78 G. J. Lewis, J. W. A. Sachtler, J. J. Low, D. A. Lesch, S. A. Faheem, P. M. Dosek, L. M. Knight, L. Halloran, C. M. Jensen, J. Yang, A. Sudik, D. J. Siegel, C. Wolverton and S. Zhang, J. Alloys Compd., 2007, 446-447, 355.

79 R. Gremaud, M. Slaman, H. Schreuders, B. Dam and R. Griessen, Appl. Phys. Lett., 2007, 91, 231916.

80 D. A. Mosher, S. Arsenault, X. Tang and D. L. Anton, J. Alloys Compd., 2007, 446-447, 707.

81 K. J. Gross and K. R. Carrington, Best Practices for the Characterization of Hydrogen Storage Materials, NREL Contract Report No. 147388, Golden, CO, 2008.

82 D. P. Broom, Int. J. Hydrogen Energy, 2007, 32, 4971.

83 K. S. W. Sing, D. H. Everett, R. A. W. Haul, L. Moscou, R. A. Pierotti, J. Rouquérol and T. Siemieniewska, Pure Appl. Chem., 1985, 57, 603.

84 A. L. Myers and P. A. Monson, Langmuir, 2002, 18, 10261.

85 A. Züttel, P. Sudan, P. Mauron and P. Wenger, Appl. Phys. A: Mater. Sci. Process., 2004, 78, 941.

86 R. Chahine and T. K. Bose, Characterization and Optimization of Adsorbents for Hydrogen Storage, 11 th WHEC, Pergamon Press, Oxford, UK, 1996.

87 H. Kabbour, T. F. Baumann, J. H. Satcher, Jr, A. Saulnier and C. C. Ahn, Chem. Mater., 2006, 18, 6085.

88 J. F. Lynch, A. J. Maeland and G. G. Libowitz, Z. Phys. Chem. N. F., 1985, 145, 51.

89 H. K. Chae, D. Y. Siberio-Pérez, J. Kim, Y.-B. Go, M. Eddaoudi, A. J. Matzger, M. O'Keeffe and O. M. Yaghi, Nature, 2004, 427, 523.

90 M. Eddaoudi, J. Kim, N. Rosi, D. Vodak, J. Wachter, M. O'Keeffe and O. M. Yaghi, Science, 2002, 295, 469.

91 S. Kaye, A. Dailly, O. M. Yaghi and J. R. Long, J. Am. Chem. Soc., 2007, 129, 14176.

92 C. Aardahl, presented in part of the 2006 to 2008 DOE Annual Merit Reviews, Arlington, VA (2008 presentation accessed on 5/20/09 http://www.hydrogen.energy.gov/pdfs/review08/stp_3_aardahl.pdf).

93 F. Zheng, S. D. Rassat, D. J. Helderandt, D. D. Caldwell, C. L. Aardahl, T. Autrey, J. C. Linehan and K. G. Rappé, Rev. Sci. Instrum., 2008, 79, 084103. 
94 M. M. Dubinin and V. A. Astakhov, Izv. Akad. Nauk SSSR, Ser. Khim. (Eng. Transl.), 1971, 1, 5.

95 B. Bogdanovic, R. A. Brand, A. Marjanovic, M. Schwickardi and J. Tolle, J. Alloys Compd., 2000, 302, 36.

96 Z. Xiong, J. Hu, G. Wu, P. Chen, W. Luo, K. Gross and J. Wang, J. Alloys Compd., 2005, 398, 235.

97 J. Yang, A. Sudik, D. J. Siegel, D. Halliday, A. Drews, R. O. Carter, III, C. Wolverton, G. L. Lewis, J. W. A. Sachtler, J. J. Low, S. A. Faheem, D. A. Lesch and V. Ozoliņš, Angew. Chem., Int. Ed., 2008, 47, 882.

98 P. Mauron, F. Buchter, O. Friedrichs, A. Remhof, M. Bielmann, C. N. Zwicky and A. Züttel, J. Phys. Chem. B, 2008, 112, 906.

99 V. Ozolinš, E. H. Majzoub and C. Wolverton, J. Am. Chem. Soc., 2009, 131, 230.

100 S.-J. Hwang, R. C. Bowman, Jr, J. W. Reiter, J. Rijssenbeek, G. L. Soloveichik, J. C. Zhao, H. Kabbour and C. C. Ahn, J. Phys. Chem. C, 2008, 112, 3164.

101 N. Ohba, K. Miwa, M. Aoki, T. Noritake, S. Towata, Y. Nakamori, S. Orimo and A. Züttel, Phys. Rev. B: Condens. Matter Mater. Phys., 2006, 74, 075110.

102 S. Orimo, Y. Nakamori, N. Ohba, K. Miwa, M. Aoki, S. Towata and A. Züttel, Appl. Phys. Lett., 2006, 89, 021920.

103 The related compound, $\mathrm{Li}_{3} \mathrm{BN}_{2} \mathrm{H}_{8}$, has been experimentally observed to release more than $10 \mathrm{wt} \% \mathrm{H}_{2}$ : see ref. 41 .

104 D. J. Siegel, C. Wolverton and V. Ozolinšs, Phys. Rev. B: Condens. Matter Mater. Phys., 2007, 75, 014101.

105 C. Wolverton, V. Ozolinš and M. Asta, Phys. Rev. B: Condens. Matter Mater. Phys., 2004, 69, 144109.

106 C. R. Miranda and G. Ceder, J. Chem. Phys., 2007, 126, 184703.

107 G. Wolf, J. Baumann, F. Baitalow and F. P. Hoffman, Thermochim. Acta, 2000, 343, 19.

108 J. Baumann, F. Baitalow and G. Wolf, Thermochim. Acta, 2005, 430, 9 .

109 B. Panella, M. Hirscher, H. Pütter and U. Müller, Adv. Funct. Mater., 2006, 16, 520.

110 Adapted from G. Thomas, presented to FreedomCAR Hydrogen Storage Technical Team, November, 2007.

111 The range of entropy values are drawn from the Sandia hydride database: http://hydpark.ca.sandia.gov. The nomenclature "maximum", "minimum" and "typical" for entropies refer to the range of values found for hydrides in this database.

112 R. W. P. Wagemans, J. H. van Lenthe, P. E. de Jongh, A. Jos van Dillen and K. P. de Jong, J. Am. Chem. Soc., 2005, 127, 16675.

113 C. Wolverton, D. J. Siegel, A. R. Akbarzadeh and V. Ozolinšs, J. Phys.: Condens. Matter, 2008, 20, 064228.

114 Although our example uses desorption as an example PCT measurement, the procedure is essentially identical for hydrogen uptake.

115 T. B. Flanagan and W. A. Oates, Hydrogen in Intermetallic Compounds I, In Topics in Applied Physics, ed. L. Schlapbach, Springer, Berlin, 1988, pp. 49-85.

116 Hydrogen Technology, Mobile and Portable Applications, ed. Aline Léon, Springer, Berlin, 2008, pp. 501-520.

117 C. N. Park, S. Luo and T. B. Flanagan, J. Alloys Compd., 2004, 384, 203.

118 P. Hohenberg and W. Kohn, Phys. Rev., 1964, 136, B864.

119 W. Kohn and L. J. Sham, Phys. Rev., 1965, 140, A1133.

120 J. M. Rickman and R. LeSar, Annu. Rev. Mater. Res., 2002, 32, 195

121 Calculating the phonon spectrum can be computationally intensive for crystals with many symmetry-non-equivalent atoms. Also, as this approach accounts only for vibrational contributions to the free energy, it neglects other degrees of freedom- such as configurational entropy - that may be relevant for some compounds.

122 S. V. Alapati, J. K. Johnson and D. S. Sholl, J. Phys. Chem. B, 2006, 110, 8769.

123 S. V. Alapati, J. K. Johnson and D. S. Sholl, Phys. Chem. Chem. Phys., 2007, 9, 1438.

124 S. Hummelshøj et al., J. Chem. Phys., 2009, 131, 014101.
125 Y. Nakamori, K. Miwa, A. Ninomiya, H. Li, N. Ohba, S. Towata, A. Züttel and S. Orimo, Phys. Rev. B: Condens. Matter Mater. Phys., 2006, 74, 045126.

126 S. V. Alapati, J. K. Johnson and D. S. Sholl, J. Phys. Chem. C, $2008, \mathbf{1 1 2}, 5258$.

127 W.-Q. Deng, X. Xu and W. A. Goddard, Phys. Rev. Lett., 2004, 92, 166103 .

128 Y.-H. Kim, Y. Zhao, A. Williamson, M. J. Heben and S. B. Zhang, Phys. Rev. Lett., 2006, 96, 016102.

129 T. Yildirim and S. Ciraci, Phys. Rev. Lett., 2005, 94, 175501.

130 H. Lee, W. I. Choi and J. Ihm, Phys. Rev. Lett., 2006, 97, 056104.

131 Q. Sun, P. Jena, Q. Wang and M. Marquez, J. Am. Chem. Soc., 2006, 128, 9741.

132 A. R. Akbarzadeh, V. Ozoliņš and C. Wolverton, Adv. Mater., 2007, 19, 3233

133 A. R. Akbarzadeh, C. Wolverton and V. Ozolins, Phys. Rev. B: Condens. Matter Mater. Phys., 2009, 79, 184102.

134 J. Maddox, Nature, 1988, 335, 201.

135 Y. Filinchuk, D. Chernyshov and R. Cerny, J. Phys. Chem. C, 2008, 112, 10579.

136 E. H. Majzoub and V. Ozolinš, Phys. Rev. B: Condens. Matter Mater. Phys., 2008, 77, 104115.

137 V. Ozolinšs, E. H. Majzoub and C. Wolverton, Phys. Rev. Lett., $2008, \mathbf{1 0 0}, 135501$

138 C. W. Glass, A. R. Oganov and N. Hansen, Comput. Phys. Commun., 2006, 175, 713.

139 A. Sudik, J. Yang, D. Halliday and C. Wolverton, J. Phys. Chem. C, 2007, 111, 6568 .

140 U. Bösenberg, S. Doppiu, L. Mosegaard, G. Barkhordarian, N. Eigen, A. Borgschulte, T. R. Jensen, Y. Cerenius, O. Gutfleisch, T. Klassen, M. Dornheim and R. Bormann, Acta Mater., 2007, 55, 3951.

141 A. F. Voter, F. Montalenti and T. C. Germann, Annu. Rev. Mater. Res., 2002, 32, 321.

$142 \mathrm{H}$. Johnsson, G. Mills and K. W. Jacobsen, Classical and Quantum Dynamics in Condensed Phase Simulations, World Scientific, Singapore, 1998, p. 385.

143 H. Gunaydin, K. N. Houk and V. Ozolinšs, Proc. Natl. Acad. Sci. U. S. A., 2008, 105, 3673 .

144 S. Chaudhuri, J. Graetz, A. Ignatov, J. J. Reilly and J. T. Muckerman, J. Am. Chem. Soc., 2006, 128, 11404.

145 G. D. Sandrock and P. D. Goodell, J. Less Common Met., 1984, 104, 159.

146 O. Bernauer, J. Topler, D. Noreus, R. Hempelmann and D. Richter, Int. J. Hydrogen Energy, 1989, 14, 187.

147 D. Mosher, presented in part of the 2008 DOE Annual Merit Review, Arlington, VA, June, 2008, accessed 5/20/09 (http:// www.hydrogen.energy.gov/pdfs/review08/st_41_mosher.pdf).

148 Adapted from M. Heben, Overview of the DOE Hydrogen Sorption Center of Excellence, 2008 DOE Hydrogen Program Annual Merit Review Proceedings, http://www.hydrogen.energy. gov/pdfs/review08/st 15 heben.pdf.

149 Fuel Cell Technical Targets for Automotive Applications: http://wwwl.eere.energy.gov/hydrogenandfuelcells/mypp/pdfs/ fuel_cells.pdf (accessed 5/20/09).

150 W. Luo and K. Stewart, J. Alloys Compd., 2007, 440, 357.

151 J. Zhang, T. S. Fisher, P. V. Ramachandran, J. P. Gore and I. Mudawar, J. Heat. Transfer, 2005, 127, 1391.

152 J. O. Jensen, A. P. Vestbo, Q. Li and N. J. Bjerrum, J. Alloys Compd., 2007, 446-447, 723.

153 A. Burke and M. Gardiner, Hydrogen Storage Options: Technologies and Comparisons for Light-Duty Vehicle Applications, University of California, Davis, 2005, http://its.ucdavis.edu/.

154 J. Hyde, 2001 Reuters World Environment News, http:// www.planetark.org/dailynewsstory.cfm/newsid/13671.story.htm, December 12.

155 F. S. Suda, in Handbook of Fuel Cells-Fundamentals: Technology and Applications, ed. W. Vielstich, H. A. Gasteiger and A. Lamm, John Wiley \& Sons, Hoboken, NJ, 2003, vol. 3, pp. 115-120. 